\title{
An Ethnographic Analysis of the Current Whistleblowing Landscape in the Canadian Public Service
}

by

\author{
Chi Kim Tran
}

A thesis submitted to the Faculty of Graduate and Postdoctoral Affairs in partial fulfillment of the requirements for the degree of

Master of Arts

in

Anthropology

Carleton University

Ottawa, Ontario, Canada

C2011, Chi Kim Tran 
Library and Archives

Canada

Published Heritage

Branch

395 Wellington Street

Ottawa ON K1A ON4

Canada
Bibliothèque et

Archives Canada

Direction du

Patrimoine de l'édition

395 , rue Wellington

Ottawa ON K1A ON4

Canada
Your file Votre référence

ISBN: 978-0-494-87808-8

Our file Notre référence

ISBN: $978-0-494-87808-8$

\section{NOTICE:}

The author has granted a nonexclusive license allowing Library and Archives Canada to reproduce, publish, archive, preserve, conserve, communicate to the public by telecommunication or on the Internet, loan, distrbute and sell theses worldwide, for commercial or noncommercial purposes, in microform, paper, electronic and/or any other formats.

The author retains copyright ownership and moral rights in this thesis. Neither the thesis nor substantial extracts from it may be printed or otherwise reproduced without the author's permission.
AVIS:

L'auteur a accordé une licence non exclusive permettant à la Bibliothèque et Archives Canada de reproduire, publier, archiver, sauvegarder, conserver, transmettre au public par télécommunication ou par l'Internet, prêter, distribuer et vendre des thèses partout dans le monde, à des fins commerciales ou autres, sur support microforme, papier, électronique et/ou autres formats.

L'auteur conserve la propriété du droit d'auteur et des droits moraux qui protege cette thèse. $\mathrm{Ni}$ la thèse ni des extraits substantiels de celle-ci ne doivent être imprimés ou autrement reproduits sans son autorisation.
In compliance with the Canadian Privacy Act some supporting forms may have been removed from this thesis.

While these forms may be included in the document page count, their removal does not represent any loss of content from the thesis.
Conformément à la loi canadienne sur la protection de la vie privée, quelques formulaires secondaires ont été enlevés de cette thèse.

Bien que ces formulaires aient inclus dans la pagination, il n'y aura aucun contenu manquant. 


\section{ABSTRACT:}

This thesis ethnographically explores how whistleblowers, as individual actors and as members of a collective, have been transforming the whistleblowing landscape of the Canadian public service. Traditionally, whistleblowing in the public service has been understood to be isolated events of public servants using the media to call the public's attention to acts of corruption that are linked directly to the misuse of public funding. This research thesis provides the evidence that whistleblowing is rather a process in which personal ethics and ideologies are negotiated with those of the organizations over matters that constitute a new kind of corruption - institutional corruption. Drawing on Victor Turner's concepts of liminality and communitas, this thesis examines the formation of a whistleblower's group and its attempts to provide support to its members and to improve the ability of Canadian civil servants to challenge institutional corruption. Assessing its success and limitations, this research posits that these whistleblowers have contributed to new understandings of whistleblowing within the Canadian public service through their participation in the politicization of whistleblowing and through their personal and communal transformations. 


\section{ACKNOWLEDGEMENT:}

Getting to this point has been an extremely valuable learning experience and personal development in all aspects. Some of the lessons are laid out here to be shared with others, and many remain deep-rooted in my mind and my heart. They will forever be part of the lens through which I see the world. For that, I'd like to send my deepest gratitude to all those who were involved in this project. I would like to thank Dr. Blair Rutherford and Dr. Bernhard Leistle for their guidance and support in bringing this research thesis from an abstract concept to its completion, my mentor whose wisdom and generosity had helped me to appreciate the complexities of life, and those whose love and support provided the balance that was crucial to the successful completion of this journey. I would like to acknowledge the Gadfly and its members for their contributions in making it possible to add another angle to the public's knowledge on whistleblowing, the importance and the complexities of this act - thank you for your courage! 
TABLE OF CONTENTS:

CHAPTER

PAGE

1. INTRODUCTION 1

a. Methodology 4

b. Conceptual Frameworks 11

2. THE WHISTLEBLOWING JOURNEY - A NEGOTIATED PROCESS 20

a. Perception Of Wrongness 22

b. From Reluctant Dissenters to Persistent Resisters 33

i. Internal to External Whistleblowing - A Process 38

ii. Marginalization of the Reluctant Dissenters 47

iii. Struggles of the Persistent Ethical Resisters 51

3. CHALLENGES OF IN-ACTION SOLIDARITY

a. The Challenges that come with Structure 57

i. Dinner Meetings - The Transition into Structure $\quad 59$

$\begin{array}{ll}\text { ii. Funding } & 70\end{array}$

$\begin{array}{ll}\text { iii. Space } & 72\end{array}$

iv. Case Management 74

b. From Whistleblowing to Mobilization and Back 77

i. Social Action Continua and Their Challenges $\quad 79$

ii. Driving Forces Behind the Movement between 84

Whistleblowing and Mobilization 
a. The Public Service Disclosure Protection Act (PSDPA) 91

b. The Office of the Public Service Integrity 98

Commissioner of Canada (OPSIC)

5. CONCLUSION 107

a. Opportunities for Future Research 113

i. Perspective of Whistleblowers' Antagonists 113

ii. Digital Technologies as Political Technologies 115

iii. Blow the Whistle without Being the Whistleblower $\quad 117$

$\begin{array}{ll}\text { BIBLIOGRAPHY } & 120\end{array}$ 


\section{Chapter I - INTRODUCTION}

Traditionally, whistleblowing in the public service has been understood to be isolated events that result from public servants using the media to call the public's attention to examples of corruption that are linked directly to the misuse of public funding. However, the media exposure of individual cases and the understanding of corruption in monetary values only provide a partial representation of the situation in Canada. This thesis ethnographically explores how whistleblowers, as individual actors and as members of a collective, have been transforming the whistleblowing landscape of the Canadian public service.

The first part of this thesis explores the process in which whistleblowers negotiate their personal ethics and ideologies with those found in the organizational culture of their employers over issues that would not be commonly recognized as corruption. This research provides supporting evidence that highlights the emergence of a new concept of corruption, institutional corruption, which is defined as acts that weaken the publics' trust in public institutions (Edmond J. Safra Foundation Center for Ethics, n.d.). Most whistleblowers have a high level of trust in the values of the public institutions that employ them. Consequently, they begin their whistleblowing journey as the reluctant dissenters who naively believe that their employers would appreciate efforts made to point out acts that are inconsistent with the organizations' mandates. Contrary to their expectations, retaliation and marginalization are the responses that they receive from employers. Consequently, this backlash only further drives whistleblowers to the path of persistent ethical resisters, existing on the periphery of a society in which they once 
belonged.

Marginalized in their professional organizations, whistleblowers of my study exist in a liminal space as they no longer participate in the structure of their former organizations; however, in their marginalized state, they find a sense of spontaneous communitas and shared experience with other whistleblowers. This spontaneous feeling of comradeship has fostered the emergence of a non-governmental organization (NGO) that provides grassroots (whistleblower-to-whistleblower) support to whistleblowers and advocates for legislative and administrative whistleblowers protection. To protect the identity of the informants, I have given the pseudonym "Gadfly" to this NGO.

The Gadfly, which was incorporated sometime in the last five years, is composed mostly of whistleblowers. Its mandate is to 'advance integrity and accountability', advocate for whistleblowers, and support them in dealing with the challenges that occur in their whistleblowing ordeals. By 2009 , the Gadfly had taken its advocacy into one of the most popular forms of contemporary social networking media - Facebook. The Gadfly considers itself as a grassroots organization that supports whistleblowers. The activities of the organization include providing peer-to-peer support for whistleblowers, raising awareness about whistleblowing in the social and political arenas, and representing interests of whistleblowers in the development of legislations and practices used to address issues that affect whistleblowers. The Gadfly is one of the first Canadian collective bodies of whistleblowers that aims to serve several functions in the context of whistleblowing. Its objective is to exist as a self-help group as well as an advocacy group that not only operates as a watchdog of the federal state's actions and directions, but also 
as a contributor to the evolution of the state's legislation and actions on the issue of whistleblowing.

The second and third parts of this research thesis explore the Gadfly as a new phenomenon of whistleblowing, in which whistleblowers transform the whistleblowing landscape by moving back and forth on an action continuum - from being lonesome actors to being members of the collective. As its membership grows, this thesis will show that the Gadfly has tried to develop a structure for their collective existence. However, in trying to create structure, the Gadfly has been confronted with a multitude of problems that threaten to destroy the communitas that has united them as a mobilized group of persistent ethical actors. Furthermore, I will argue that the conditions that engender the creation of the Gadfly - the liminality that led to the development of the communitas, and the action continuum that allows whistleblowers to go beyond the traditional individual struggles and leverage off the strength of the collective - are also the factors that have deterred the organization from moving towards its vision of providing grassroots and advocacy support for whistleblowers. Despite these challenges, the Gadfly and its members, since conception, have collectively and individually contributed to the macro and micro transformations in the whistleblowing landscape of the Canadian public service.

The macro transformation takes places through the politicization of whistleblowing by individual whistleblowers, NGOs that advocate for whistleblowers protection including the Gadfly, the politicians and the state. The state and its politicians alternately weave whistleblowing into political platforms or de-politicize whistleblowing through regulations of the disclosure regime to serve their own political agendas. However, the 
strategy of highlighting whistleblowing in the public space to gain political power and removing it from the public space in order to minimize the involvement of the public have unexpected consequences. The NGOs and whistleblowers have turned these political technologies of the state into their own tools of democracy, through which they exert their agency, as individuals and as a collective, in trying to transform the landscape of whistleblowing. Their efforts have led to recent changes of the central tools that the Canadian government has created in order to regulate the disclosure of wrongdoings in the public service. The review of the current Public Service Disclosure Protection Act and the re-organization of the Office of Public Service Integrity Commissioner are two of these significant changes. At the micro level, the transformation takes place in the daily lives of the whistleblowers; the grassroots support that the Gadfly offers to its members has helped a number of whistleblowers to be more informed of the challenges that they are, and will be, facing as they go through the whistleblowing process. These transformations are indications that conversations are beginning to take place on how whistleblowers can be used as an asset in the fight against corruption towards transparency and accountability in the Canadian public service.

\section{Methodology}

The intention of this research is to gain an understanding of whistleblowing as experienced by the whistleblowers. The ethnographic methods of this research include: participant observation in meetings, social gatherings, email exchanges within the Board of Directors, and semi-structured interviews with thirteen members of the Gadfly, ten of which are whistleblowers and three are non-whistleblowers. In order to protect the 
anonymity of the informants involved in this research, the organization and its members have been given pseudonyms. Informants for the interviews were recommended by the Gadfly's directors; this approach was used in order to focus the scope of analysis on the experiences of those whose agency were most influential to the construction of this organization and its impacts on the overall politics of whistleblowing. Collectively, the whistleblowers recommended by the directors represent the different components that the members of Gadfly use to frame their discourse and the political technologies that they use to foster the desired transformation. Seven out of the ten whistleblowers were either current or former directors of the organization. ${ }^{1}$ Two of the remaining three whistleblowers were members, and the third was a client who was seeking support from the organization. The three non-whistleblowers were all members of the Board of Directors. Ten out of the thirteen informants were current or former employees of the Canadian pubic service. The Gadfly is based in Ottawa where most of its members reside, although its network spans from coast to coast.

In response to my request for recommendations of interviewees, a number of directors suggested whistleblowers who lived outside of Ottawa and who had been in touch with the organization to access the grassroots support. They also suggested people who had impacted the politics of whistleblowing significantly, but were not members of The Gadfly. I chose to not include these actors in the research in order to focus on the nucleus of the organization's developments, and the power relations that exist in this locality; although a bigger project would benefit from venturing further outside of this center. The collaboration of Gadfly members also helped me to identify sources that reinforce their

${ }^{1}$ Changes in the Board of Directors took place several times during my fieldwork. 
discursive strategy, such as Canadian government websites, relevant media coverage, as well as links to websites of non-governmental actors discussing topics relating to whistleblowing. The most significant of these sources are some of the informants' own websites in which they reveal their whistleblowing stories and sometimes their endeavors after the whistleblowing events. In addition, a number of the informants volunteered documents that are not yet public information in order to help me better understand the dynamics involved in their situations.

A collaboration occurred throughout my research between myself and key members of the Gadfly, as I consulted and updated them on the progress of my research, and provided them with any non-confidential information that I encountered during the research which I believed to be an asset to their organization. Therefore, the departure point of the research, with respect to its design and the scope of ethnographic data, is largely based on the knowledge and experiences of the informants, as well as the trust and comfort that each member of The Gadfly has had towards me as a researcher.

Furthermore, access to the inner workings of the politics of whistleblowing and the corresponding mechanisms of the state was also enhanced by my own experiences with the disclosure regime of the Canadian public service. I have been working for the Canadian public service for the last nine years. Throughout these years of service, I have experienced and witnessed how an individual's agency can shape the organizational culture and the practices of my organization, and to some extent the larger institution the Canadian public service. I have also seen how the institution affects individuals' lives; in some cases, the impact that the institution has on its employees reaches the 
foundational make-up of the employees' views of their self and the world. A few years before my academic engagement in whistleblowing, I followed the internal disclosure regime which is the administrative system and the personnel that are put in place to deal with disclosures in the public service. My aim was to support some individuals, who were receiving reprisals for challenging the practices that contributed to the inefficiency of an organization inside the public service. This experience has provided the necessary insider knowledge on the disclosure processes of the public service and the appreciation of the interwoven complexity of whistleblowing. This journey was also crucial in gaining the trust of the Gadfly's members, not only in my capacity as a researcher, but also in my ability to communicate with the organization's members regarding its current and future developments as an advocacy group for whistleblowers' protection.

To be engaged in the struggle of the subjects of one's research is a political stance that many anthropologists have considered. Engaged anthropology has warranted many heated debates among scholars in the discipline. On one end of the spectrum are voices such as Scheper-Hughes who proposes a new form of anthropology that she coins "militant anthropology" (Scheper-Hughes, 1995) which calls for more active engagement of anthropology in lending its voice to the oppressed whose struggles provide the research materials that sustain the continuity of the discipline: "We can... exchange gifts based on our labors, use book royalties to support radical actions, and seek to avoid the deadening treadmill of academic achievement and in this way subvert the process that puts our work at the service of the scientific, academic factory" (Scheper-Hughes, 1995: 420). On the other end of the spectrum are those who believe that the academic integrity of anthropology as a social science must be upheld with an objectivity that requires a certain 
distance from the research subject. The worries that are associated with Engaged Anthropology can be heard in Keesing's warning of the unavoidable bias that exists in native anthropologists (Keesing, 1989). One of the themes that has emerged from these debate is the political positioning of anthropologists. For many anthropologists, the politics of actions are inherent in their anthropological fieldwork. Any anthropological research that explores a social world composed of political thoughts and actions already has biases at the beginning of the project. Scholarship inspired by the political world, even in its broadest sense, is a form of political action (Englund, 2006: 26).

There are two prominent forms of engagement that are being contested in the discipline of anthropology: the native anthropologists like Darren J. Ranco who has to defend the potential bias in his research on American Indian nations because he is a Native American (Ranco, 2006), and the activist anthropologists like Scheper-Hughes who transforms the research subject of organs donation into an ethical project, the Organ Watch project, through her involvement in the subject as a medical anthropologist and the director of the project (Scheper-Hughes, 2007). Scheper-Hughes' activism often pushes the boundaries of anthropology and triggers debates among colleagues about the risk that her actions may "contaminate" the discipline (Anthropologi.info, August 7, 2009). Due to my background and the direction that $I$ have chosen for this research, my position as a researcher falls into both forms of engagement. For this research, the informants were selected based on two criteria: an employment with the public service, and the personal experiences with its disclosure regime. In the specific context of the research, the people who have gone through the disclosures of wrongdoings using external and/or internal channels are considered 'native' from the cultural anthropological perspective. Therefore, 
my background, as a public servant who has gone through the internal disclosure processes of the public service, constitutes my position as a native anthropologist. I also consider myself as an activist anthropologist because of my participation in the Gadfly's activities. Although I kept my involvement to the minimum, my actions, nonetheless, may have exerted certain influences on the organization and its members.

Some native anthropologists may strategically choose to use essentialism and scholarly authority in the representation and discourse of their cultures in order to support a particular political agenda (Hale, 2006: 97). The struggle between academic rigorous examining of all components that make up the fabric of our social life and the need for producing an "analytical closure" (Hale, 2006: 114) in support of certain political causes is also shared by activist anthropologists. The politics of representation, a complexity that is inherent in all social research, is enhanced when the research takes place within the native and activist context. While the position of quasi-insider and quasi-outsider is a contested space in academic work, I believe that it offers incredible insights into the research subject - an access that would not be opened to uninvolved anthropologists. Recognizing this dichotomy, Charles Briggs (1996) places both the power and responsibility of authorship on the shoulders of anthropologists. The position of authorship claims a certain authority and much responsibility to the readers and the development on the subject of discourse.

The influence of the discipline of anthropology's historical past on the representation of the research subject has been raised as an important factor that needs to be addressed in the design of the research (Keesing, 1989: 20-21). As a result, it is recommended that 
native scholars conduct self-reflexivity to reveal the influences that are shaping their perceptions of the research results, in order to be free from the hegemonic construction of their historical past (Keesing, 1989: 25). In addition to using self-reflexivity as a tool to analyze the dynamics that I bring into the research, I have also taken periodic breaks between different phases of the research. The fieldwork commenced in May 2010 and was completed in February 2011. During these breaks, I removed myself completely from the research by physically going away from the field site, which is also my place of residence, ${ }^{2}$ and/or temporarily disconnected from the informants and the whistleblowing subject. These breaks took place during the transitions between different phases of the research. I discovered that the breaks were necessary for gaining the distance from my deep engagement of the subject and the actors. The temporary removal from the field allowed me to see the patterns of power relations and political technologies found in the whistleblowing landscape without being drawn completely into these dynamics. In addition, the nature of academic work also automatically creates a certain distance to the subjects and objects of the research. This academic distance is engendered by connecting the locality of one's field site to the global scale of the research subject. I have done this by situating the results of my research and the subsequent analysis within the context of other research that has been conducted on the same subject.

\footnotetext{
${ }^{2}$ I live and work in Ottawa; this city is also the place of residence and employment for the informants of this research.
} 


\section{Conceptual Frameworks}

This thesis research provides evidence that whistleblowing is indeed a negotiated process in which the outcomes are dependent on the power struggles between the whistleblowers and their interlocutors. There are many who may dissent against their immediate managers but do not persevere in their criticisms by taking the issues to higher authorities in their organizations, following the internal disclosure process, or taking their dissent into the public sphere. This research does not ascribe these individuals as 'whistleblowers'. Whistleblowing is a journey in which the whistleblowers travel from the position of reluctant dissenters to that of persistent ethical resisters. The persistency is a manifestation of the transformative power of the whistleblowing experience, whereby 'the whistleblower' becomes the "master status" for these individuals (Rothschild \& Miethe, 1999: 121). This master status encompasses other aspects of their lives and becomes the underlining force for their engagement in the public service's accountability and whistleblowers' protection advocacy. Each step along this journey is dependent on the individual outcome of the negotiation. The complex techniques through which these political subjects are created by self and others through these negotiations can be revealed through the dissection of power relations involved in the problematization of whistleblowing.

Foucault suggests that to understand power, one must look at the forms of resistance that come into existence as a direct response to the forms of power: "Using this resistance as a chemical catalyst so as to bring to light power relations, locate their position, and find out their point of application and the methods used. Rather than analyzing power from the 
point of view of its internal rationality, it consists of analyzing power relations through the antagonism of strategies." (Foucault, 1982: 780). In this context, power is a social phenomenon that rises from the interlocking of power relations with relations of resistance strategies, and the results of their interactions (Foucault, 1982: 795). In his later works, Foucault asks that the study of governmentality go beyond the tactics and practices that the state uses to rule over the population, and that governmentality should be considered as a space made of relations and "a point of contact where techniques of the self interact with techniques of domination or power" (Asdal, 2008). At this point, in this space, the power relations are not static. The role of each actor is contingent on the sphere in which their power resides, and this residency is temporary and directly dependent on the role that the actors adopt. This intricacy of cause and effect produces an organic web of power relations that evolves through time and events. Foucault (1982: 794) articulates this organic character of power in the following passage:

In effect, between a relationship of power and a strategy of struggle there is a reciprocal appeal, perpetual linking and a perpetual reversal. At every moment the relationship of power may become a confrontation between two adversaries. Equally, the relationship between adversaries in society may, at every moment, give place to the putting into operation of mechanism of power.

In the context of this thesis, 'political technologies' are the strategies that lead to the politicization of whistleblowing. The strategies that are used to politicize whistleblowing are not only employed by the state and the politicians, but are also used by whistleblowers' advocates to influence the developments of whistleblowers' protection. Therefore, the political technologies that are employed in these interplays of power relations must not only be considered as "techniques of domination" but also as "tools for democracy" (Asdal, 2008: 13). These theoretical lenses provide the necessary frameworks to examine 
the "action continuum" (De Maria, 2008) that connect the individual to the collective dimensions of the whistleblowing phenomenon. Furthermore, this thesis will show that the technologies used by the Canadian public service to politicize and depoliticize whistleblowing are also transformed into the tools with which whistleblowers and their advocates use to influence the politics of whistleblowing. The concept of action continuum stems from De Maria's contemplation of the possible co-productivities between whistleblowing and protesting (De Maria, 2008). The term "action continuum" refers to the continuity that De Maria sees between whistleblowing and mobilization through protesting as acts of ethical resistance. In his exploration, De Maria suggests that future research is necessary to further explore the field of ethical resistance by examining the potentiality of an alliance between whistleblowers and organizational protesters (De Maria, 2008: 877). The following questions were suggested for this research potential: "To what extent is it possible for ethical resisters to move through a social action continuum from whistleblowing to mobilization and perhaps back again? If there is tactical fluidity, what drives this movement?" (ibid). The ethnography of the Gadfly provides evidence that an action continuum does exist in the actions of whistleblowers although there are limitations. The research also offers explanations on what drives the movement between whistleblowing and mobilization. However, this research does not make the connection between two different groups of actors involved in the field of ethical resistance; instead it explores the continuity in different forms of actions from one group of actors: the whistleblowers.

An analysis of political technologies employed by political subjects in this landscape also demonstrates how whistleblowing becomes politicized at different scales as it fluctuates 
from the personal to the global. At the personal level, individuals transform the strategies that the state uses to contain disclosures inside the system into tools that help them draw the state's attention to the specific wrongdoings that they have blown the whistle on. The public administrative arm of the state tries to contain the issue of wrongdoings in an apolitical space through the creation and implementation of the Public Service Disclosure Protection Act (PSDPA). ${ }^{3}$ On the other hand, the politicians in power use whistleblowers, their interlocutors and the legislations in their political campaigns, to advance or maintain their political standing, thereby escalating the politicization of whistleblowing into the national scale. Political technologies that are based on individuals, legislations and their implementations are also employed by NGOs, such as The Gadfly, to advance changes that support whistleblowers' protection. These forms of politicization at the national level are brought to the international scale when NGOs, such as Transparency International, incorporate the developments of the state and non-state actors in its global mobilization platform against corruption.

By engaging in disclosures and the advocacy of whistleblowers' protection, the Gadfly's members are stepping out of the structures that had formerly constructed their social world. The act of whistleblowing does not only trigger changes in these individuals' acceptance in their professional institutions, but also in other social structures, including personal lives. Challenging the dominant social order results in what Turner (1969) coined as "liminality", a condition of existing in ambiguity. During this period, individuals "elude and slip through the network of classifications that normally locate states and positions in cultural space. Liminal entities are neither here nor there, they are

\footnotetext{
${ }^{3}$ Chapter Four of the thesis will provide more in-depth discussion on the PSDPA.
} 
betwixt and between the positions assigned and arrayed by law, custom, convention, and ceremonial" (Turner, 1969: 95). People in liminality often experience a sense of 'spontaneous communitas' with one another. Spontaneous communitas is used to describe the phenomenon in which people relate to each other as they present themselves in the here and now without "the culturally defined encumbrances of his role, status, reputation, class, caste, sex or other structural niche" (Turner, 1969: 48). However, this spontaneous communitas ceases to exist at a certain point and the need for structure arises (Turner, 1969: 49). People who have experienced spontaneous communitas eventually want to establish structure and order to achieve common goals while they simultaneously attempt to maintain the spontaneous communitas that has brought them together. Turner (1969: 49) describes this phenomenon as "normative communitas" - a perduring social system that originates from the ideals of "freedom", "liberation", or "love". Normative communitas have many challenges including the inability to maintain the spontaneous communitas, since this phenomenon cannot be legislated or normalized (Turner 1969: 49).

The Gadfly is founded on the spontaneous communitas experienced by whistleblowers while they are marginalized within their organizational structure. The Gadfly was founded on the solidarity of individuals who became whistleblowers and members of the organization because they shared the same ideology with respect to the rights and obligations to disclose wrongdoings. In the beginning, the organization operated without any formal structure, the solidarity and the support that whistleblowers experienced from the organization were sustained in strength. However, the solidarity diminished significantly when The Gadfly tried to formalize its existence through the installation of a structure for the organization. By bringing in structure, The Gadfly faced the risk of 
losing the communitas that had been the basis of their collectivity. Turner's descriptions of the lack of structure and the instability that is associated with liminality explain not only the pre-conditions that foster the spontaneous communitas which eventually led to the Gadfly's transformation towards a normative communitas, but it also provides an underlining cause of the challenges that the Gadfly faced in moving forward with its vision. The Gadfly is founded by individuals in liminality, therefore the organization, itself, is in liminal existence. In liminality, the founders of the Gadfly reject and are rejected by the structures of their organizations, and yet they try to develop an organization based on the models of the organizational structures that no longer permit their memberships. This "betwixt and between" existence at the personal and organizational levels often become the deterrents to the execution of shared principles. However, this theory only offers the here and now; the theory lacks the link between the present and a future evolution of the current situation.

Network theories offer an explanation which links the struggles that the Gadfly experiences to the potentiality of the future. Juris provides the following theory to explain the challenges that he observes in networks of anti-corporate globalization activists. As non-state actors become "cultural innovators", they create "social laboratories" where new "cultural practices and political imaginaries" (Juris, 2008: 297) are born. Many of the problems that I observed among members of the Gadfly are similar to those found in Juris' research. For the Gadfly, the experimentation that has taken place during this liminal phase is not only about the conceptualization of its own creation as an institution, but it is also about creating a "deliberative democracy," which can be understood as a model of democracy that is fostered through the transformation of the preferences of individuals 
that are involved in the decision making process (Elster, 1998, as cited in Asdal, 2008). This conceptualization of democracy can even be expanded further to include the persons affected by the decision in the decision making process. The term that is used to describe the product created through this inclusive approach is "expansive democracy" (Asdal, 2008: 13, citing Hajer \& Wagenaar, 2003). This concept is different from the traditional analysis of democracy that views democratic conditions as shaped only by actors within the political sphere. Confronted with this "dual politic" (Juris, 2008) of challenging the current infrastructure and practices found in the dominant political sphere, while trying to create an alternative that the organization is demanding of the public service, The Gadfly is faced with the same challenge that its members pose to their employers. Mainly, they are confronted with the challenge of creating an effective regime of accountability operated under a democracy that resembles the principles of a deliberative democracy, if not those of the expansive democracy.

\section{Conclusion}

Understanding the interwoven complexities that give rise to whistleblowing requires a set of theoretical lens that regards whistleblowing as a process of negotiations, in which the actors transform themselves and the landscape of whistleblowing. The phenomenon of whistleblowing can be seen as a dance that emerges through individual dancers whose movements are dependent on each other and the music that evolves along with the dancers. 
Chapter Two discusses the negotiation process of whistleblowing that has transformed many members of The Gadfly from reluctant dissenters of the Canadian public service to persistent ethical resisters advocating for whistleblowers' protection and anti-corruption in the public service. Ethics is the new buzzword that is used by state and non-state actors in their discourses on corruption prevention and management. There are pamphlets and even courses offered on how individual employees can perform his/her duties in an ethical way. However, ethics is not universal to all individuals; ethics exist on a scale. Each person finds her/his comfort on a different position on the ethical scale. Some people have a single point in all situations while most people's ethical positions are actually influenced by his/her external environment. Many whistleblowers are marginalized because the distance between the positions of their own ethics is too far from those of their organizations. Individual whistleblowing events crystallize when employees find themselves marginalized. Pushed outside of the acceptable space of their organizations, whistleblowers create a new social space in which the solidarity in their ideology of accountability and transparency goes through a characteristic transformation found in many social movements that challenge the dominant political powers. This journey travels from a liminal phase to a space in which comrades struggle in the efforts to form an organized structure that advocates for a new ideology whose application is still under experimentation. This transformation, which the Gadfly hopes will take them from solidarity in principle to solidarity in actions, is discussed in Chapter Three. The question of whether the Gadfly and its members have made any impact on the whistleblowing landscape is addressed in Chapter Four, where the emergence of the politicization of whistleblowing through key events that brought whistleblowing into the national and international political spheres, are discussed. The Gadfly members are not solely 
responsible for these events, rather they are part of the power relations through which the transformations of the Canadian whistleblowing landscape emerge. Together, these three dimensions provide an angle of whistleblowing that has not yet been addressed by current works on the subject. The thesis concludes with several suggestions for future research that emerge from my fieldwork as crucial for further understanding of whistleblowing. 
Chapter II - THE WHISTLEBLOWING JOURNEY - A NEGOTIATED PROCESS

Corruption is commonly understood as unethical acts committed by individuals or groups for personal gains. As a result, the label and the recognition of corruption are only warranted when there is concrete evidence demonstrating the financial and opportunistic gains from the acts of corruption. However, a new definition is being raised in the policy and academic discourse. The term "institutional corruption" is used to describe the conditions that weaken the trust of the public for a public institution, or the effectiveness of the institution in achieving its purpose (Edmond J. Safra Foundation Center for Ethics, n.d.).

This definition of corruption opens up new spaces for discourse on the subject, as it takes into account the wide and diverse range of incentives that motivate people to act against the interests of the public and the mandates of their institutions. The personal gains that are offered in these incentives include those that have been disregarded by the traditional view of corruption; these can be the long-term benefits of a steady climb on the corporate ladder, successful career in politics, guarantee of employment post service in the public sector, etc. This new definition of corruption also takes into consideration the ambiguity of unethical acts or wrongdoings that stem from the complexities inherent in individuals' responses to organizational cultures.

Individual knowledge, ethics, and personal background are important determining factors in employees' reactions toward the wrongdoings that have become the norms in their organizations. Whistleblowers tend to have more in-depth knowledge, and different 
ethical positions than most of their colleagues, especially those in the management positions. Moreover, whistleblowers are loyal to their personal and organizational ideals, rather than the physical representations (peers and superiors) of their organizations. These differences are often not expressed until certain events trigger the initial act of dissent. Once triggered, the loyalty of these individuals to such ideals can set in motion the journey from being reluctant dissenters to becoming persistent ethical actors.

In this journey, these public servants look to the internal disclosure process in search of understanding and support, only to be typically confronted with marginalization from their colleagues and superiors. In spite of the marginalization that often forces them into a liminal space for months, if not years, some of these individuals persist in their struggles based on ethical ground until they engage the interest of the public in their fight against the system. Not all persistent ethical actors become external whistleblowers. However, the experience of being disappointed and marginalized through the internal disclosure process impacts every whistleblower, internal and external, in their professional and personal lives for years after the event. The struggles in trying to deal with the marginalization, the financial and legal implications, and negative consequences on their career prospects, foster a sense of spontaneous communitas amongst whistleblowers. This type of solidarity is the basis on which the Gadfly was founded.

This chapter presents the whistleblowing journey as a negotiated process between the whistleblowers and their interlocutors (colleagues, managers, and the public service as the employer). The negotiation starts with the differences in the perception of wrongness between whistleblowers and their interlocutors, and takes places throughout their 
journeys from being the reluctant dissenters to the persistent ethical resisters. How far each individual travels in this journey is dependent on: their experiences with the internal disclosure process that has forced them from being the internal whistleblowers to the external ones; the marginalization that they face while they reluctantly dissent the orders of their superiors; and the challenges they encounter once they persist in their actions on the basis of there sense of ethical purpose.

\section{Perception of Wrongness}

Ethics is not a universal concept even though the discourse on ethics often adopts terminologies that are widely accepted without addressing the differences in the interpretation of the texts. Terminologies such as accountability, transparency, wrongdoing, and gross mismanagement are found frequently in the discourses produced by the state, whistleblowers and their advocates. However, the interpretations of these terminologies and how they apply to specific situations differ between these groups and even between individuals within each group. For the Office of the Public Service Integrity Commissioner (OPSIC), the words 'wrongdoing' and 'gross mismanagement' are used interchangeably. The former is broadly defined as "serious actions that are contrary to the public interest" (OPSIC, n.d.) while a more specific definition is given to the latter:

Gross mismanagement generally applies to very serious situations that result or could result in a breach of public interest. The following factors, among others, are considered when determining whether a situation could constitute "gross mismanagement": the seriousness of the deviation from standards, policies or practices; the functions and responsibilities of the public servant alleged to be responsible for the gross mismanagement; the seriousness and willfulness of the acts or omissions in question; the repetitive or systemic nature of the acts; the 
impact or potential impact of the mismanagement on the organization's ability to carry out its mandate; the impact or potential impact on the organization's employees, clients and the public trust (OPSIC, n.d.).

In one of their documents, the Gadfly acknowledges PSIC's definition of wrongdoing; however, the pillar on which the Gadfly lays the platform of their actions is based on the word 'accountability' which they define as:

Duties and responsibilities and answering for the performance of those duties and responsibilities. In the ideal, managers of a corporation are accountable to the board that is accountable to shareholders. In democratic government, bureaucrats are accountable to elected officials who are accountable to voters... Accountability is to people with a legitimate interest and is about controlling conduct and preventing mismanagement and misconduct... Accountability also implies that there are mechanisms by which the performance of responsibilities can be reported, heard and acted upon in a constructive manner. Shortcomings must be able to be addressed by remedial action or penalties... Thus, where there are no mechanisms to report on the performance of duties and responsibilities or no means to address poor conduct, mismanagement or misconduct, no accountability can be said to exist.

The differences in how 'accountability' and 'wrongdoing' are conceptualized and defined by The Gadfly and its interlocutors reflect the differences in perspectives that give rise to whistleblowing as individual events and as a cultural phenomenon. Ambiguity exists in each case that is considered in my research, even though all informants are able to identify the specific governmental documents that support the basis on which they deem certain actions as 'wrongdoing'. Despite the presence of official texts that support the positions of the whistleblowers, the significance of their protests against acts that ignore the written rules are often unclear to others.

The research data shows that the gap between the whistleblowers and others in the perception of wrongdoing also increases as the link between the actions that are deemed to be "wrongdoing" and its immediate impacts on the use of federal funding and the risks 
to the public becomes less evident. This means colleagues and managers are more responsive to the whistleblowers' concerns when the wrongness of the issues is understood and acknowledged by the majority of their colleagues. For example, in a study of 761 workers across the United States, Rothchild and Miethe (1999: 125) discover that organizations are more likely to right the wrongdoings raised by the whistleblowers if the issues involve "an isolated bad apple", but will respond with denials and retaliations towards the whistleblowers when the issues being raised are "systemic", meaning part of the regular way that the organization conducts business.

The view of the whistleblowers in this research and those in the study conducted by Rothchild and Meithe provide evidence of the emergence of a new concept of institutional corruption. The term institutional corruption goes beyond the isolated misuse of public funding for personal gains, to include conditions that weaken the trust of the public for a public institution or the effectiveness of the institution in carrying out its service to the public. The fact that there are people who have used whistleblowing to draw attention to the problems of this form of corruption proves the existence of this category of corruption, which is demanding for institutional responses. However, the fact that whistleblowers have difficulty getting acknowledgement for their perception of the corruption that exist in the acts to which they are calling attention, suggests that the paradigm shift is perhaps only taking place among a small faction of the public service.

In addition to the domination of the traditional understanding of corruption in the organizational culture of the public service, the semi-formal interviews conducted in this research reveal three factors that lead to the contestation in the perceptions of wrongness 
between the whistleblowers and their interlocutors: the knowledge and experiences required to understand the impacts of the acts that the whistleblowers are contesting; the form of loyalty experienced by the employees (loyalty towards the institution or the principles of the institution); and the ethical scale that influences how people conceive ethics and its violation. This ethical scale varies vastly between different individuals, and it is also dependent on the understanding of the impacts of a given action. This understanding is dependent not only where one's ethics lay on the scale, but also on whether that scale changes between work and personal life.

The understanding of the impacts of a given action is not only a matter of technical knowledge and experiences, but also of situational awareness of the work and of the institution. It is because of this reason that whistleblowers often have a hard time trying to explain their stories to others outside of their work environment. However, many whistleblowers also face the same challenge with their coworkers. The data from this research suggests that the capacity for relational understanding (the ability to make connections between a multitude of factors that could impact and/or be affected by a given decision) could be the gap between many whistleblowers and their colleagues. The whistleblowers that I interviewed seemed to be able to not only foresee the short and long term impacts, but they were also able to see the interconnectedness of a given action from many different angles. This seems to be a skill that does not resonate with the majority of their coworkers. The frustration, on the part of the whistleblowers, of not being able to share this understanding with management is especially high. Some of the informants considered the lack of this skill as the incompetency of their coworkers, while others believed that many of their colleagues, especially those in management positions, were 
more interested in pleasing higher authorities in order to climb the corporate ladder rather than doing their jobs. All of the informants expressed strongly that climbing the ladder in the public service, often did not equate to doing the best job to serve a said mandate. For example, Rob who works as a plumber for a federal department spent several years speaking out against his supervisor's disregard for the mandatory requirements to have certified plumbers present in the servicing of governmental buildings. At first, the problem seemed to be of little concern to anyone other than Rob. However, for Rob, the disregard presented a risk to the people inside these buildings. To help me understand this significance, he sketched out drawings of the plumbing system in my notebook and pointed out how omissions of simple parts could result in the contamination of the entire water system. This he considered to be the knowledge of his trade. But, for Rob it was not just about the knowledge, it was also about the ethical principle and responsibility behind that knowledge. As a plumber, he has the responsibility to ensure the safety of the water systems.

A similar ethical argument was given by another informant, Mitch, who up until 2006 had been part to the team that was responsible for the acquisition of equipment for a federal department. In 2003, Mitch refused to attend a mandatory training on a new software that the department was implementing, because he believed that the software did not work, and that its use and the corresponding training were a waste of tax payers' money. Mitch recalled that the ineffectiveness of this software was also stated by an evaluation body within the department in 2006: "30\% of the people, who [were] supposed to use it, say they cannot use it" (personal communication, January 20, 2011). Several of his colleagues shared the same view in the evaluation of the software training. 
Whereas Rob sees the act of cutting out plumbers in the servicing of water systems in governmental buildings as a health and safety risk to the employees in the building, Mitch sees the mandatory training as an unethical act because he believes that it wastes taxpayers' money. Their plights are similar, as both Rob and Mitch did not find support from their managers. Their managers were dismissive of their dissents and treated them as difficult employees. In order to continue to do his job, but also avoid having to attend a wasteful course, Mitch was forced to obtain a medical certificate from his doctor. His frustration was evident as he told me: "I need a doctor's certificate to do my job, to not waste the tax payers' money by putting me in a course that does not work." (personal communication, January 20, 2011)

While the whistleblowers I interviewed expressed their frustration about the lack of understanding that some of their colleagues and the management had on the issues that they brought forward, they also shared their disappointment in their colleagues, who understood the issue, but chose to marginalize the whistleblowers through bullying and mobbing. Their colleagues also chose to be silent on the issue, or those that did support them only did so to a certain point and then withdrew from the collective effort to deal with the issue.

Irvin, who speaks out against the incompetence and abusive management style of his boss at a government agency, considers this as a form of corruption within the public service and gives it the name 'soft corruption'. Irvin describes this phenomenon as "all too pervasive in the government; that is the corruption of personal expediency. What is going to favor me being promoted to the next level? If I speak out against something is that 
going to get me promoted? No, that is not going to get me anywhere. And they just have to see how the people who do this get treated. Dissent is not anyway shape or form promoted in the government" (personal communication, September 18, 2010). Irvin shares the following story to support his view. The Minister of his department decided that it would be beneficial to show that Canada has regulations that are equivalent with the US. Somebody within this government agency suggested that Canada align with the US in their acceptance of scissors at airports. As it stood, Canada only allowed small scissors, but because the US allows four-inch blades, the mandate was made to weaken the Canadian regulations to match those of the US. The idea was controversial from the start, since it asked for security regulations to be less stringent after the $9 / 11$ event. The union representing flight attendants "went ballistic" (ibid), because this government agency was making policy decisions without consulting them and without proper justification. Irvin's team "went through hoops" and the project went nowhere (personal communication, September 18,2010 ). The above project was created to serve a political agenda. Although the logics behind the creation of this project was extremely weak, Irvin's team carried out the project rather than voicing their disagreements to the chain of command that passed down the wishes of the Minister's office. The project was discontinued due to external circumstances not because an expert within the group brought her/his agreement to their managers.

This was one of the few examples that Irvin provided to demonstrate that "the role of the expert has been greatly eroded in the process in favor of political consideration" (personal communication, September 18, 2010). Irvin observes that ideas from ministers' offices are usually blown out of proportion by the time they reach the bottom rank of the 
reporting structure, and many people would rather go along with ideas that have buy-in through this process rather than risk jeopardizing their careers by making the efforts to have their disagreements known. The above example demonstrates a common phenomenon in the public service in which the employees are aware that certain acts are not consistent, and in this case, would be in violation of the mandate of the organization, but will go along rather than speak up and risk following the path of whistleblowing. Irvin approached this case with compliance rather than dissent, but brought up this as example of a systematic act of wrongdoings in his organization. Like Irvin, many whistleblowers that I interviewed had witnessed and complied with other acts that they considered as wrongdoings prior to the event that finally triggered their whistleblowing acts. It seemed that these individuals endured the distance between their own perception of wrongness and that of their organization, until they reach a point when their ethical position on a particular action can no longer support their compliance.

The complexity and interconnectedness between knowledge, experiences, and ethics are important in the unraveling of the differences that exist in the perception of wrongness between whistleblowers and their interlocutors. However, the common thread that ties all these factors together and propels some individuals into the path of whistleblowing is their loyalty to ideals. These values or ideals are usually combinations of those proclaimed by the public institutions that employ them, and their own principles that have been shaped by their personal experiences in life.

In this research, the whistleblowers demonstrated a strong sense of loyalty to the ideals of their organization when they call upon the written mandates or guiding principles of their 
departments as evidence of the validity of their actions. In her research on whistleblowers in South Africa, Uys argues that whistleblowers are actually compelled to blow the whistle and do not experience conflict of loyalties when they perceive that their loyalty is with the organizational norms and values (Uys, 2009: 916). This is because whistleblowers do not feel loyal to "the physical aspects of the company - buildings, executives, boards, hierarchies, colleagues - but the explicit set of mission statement, goals, value statement and code of conduct of the organization which is judged as legitimate" (Uys, 2009: 916, citing Vandekerckhove \& Commers, 2004). Uys uses the term 'rational loyalty' to make this distinction between the object of loyalty felt by most employees who do not blow the whistle on their employers when confronted with wrongdoings and that felt by the whistleblowers.

The rationality that allows whistleblowers to defend their whistleblowing decisions, using organizational ideals, is strengthened by their personal backgrounds. Rothschild and Miethe (1999: 119) discovered that $79 \%$ of the whistleblowers that they interviewed, from a sample size of 292 whistleblowers and silent observers (individuals who observed the wrongdoings but chose not to speak up), referred to personally held values as the driving force to blow the whistle. The origins of these values held by the US whistleblowers were diverse: job, profession, religion, community, family, or combination of any of these. Similar observations were also made in this research.

For example, Bob who came from a French Canadian family, chose to report his manager's disregard of the mandatory requirement to make French available in computerized financial systems in Canadian embassies located in French speaking 
countries, despite the threats of reprisals from his manager. In 1982, the Official Languages Act was incorporated into the Canadian Charter of Rights and Freedom (Office of the Commissioner of Official Languages, n.d.). Like many French-speaking Canadians, Bob considers this as the rights of every Canadian. Therefore when his boss told him that the diplomats in French speaking countries would have to learn English rather than changing the system to respect the rights to bilingualism of public servants, he protested: "As Canadians working in Paris and Brussels, or anywhere, are on Canadian soil, therefore Canadian law applies. And Canadian law says, they are entitled to work in the language of your choice. If you are going be computerizing these embassies, then they have to be allowed to access their work with these machines." (personal communication, January 29,2011 ) In this case, Bob believed so strongly in the ideal that the equality between English and French values manifested through the legislation of official languages, that he was willing to risk his job in defense of this ideal.

Another informant, Irene, was raised during a post war period when the population was being instilled with the idea that every person has the duty to speak out against wrongdoings in order to avoid future violation of human rights of similar magnitude. For Irene, this ideology has become her guiding principle and the driving force in her decision to spend years speaking out against acts that she considers as contradictory to the mandate under which she serves as an employee of a federal department. One of her major concerns is the frequency of the department's scientists being forced to make favourable decisions on the regulation of commercial products that are not based on their scientific judgments, but rather are based on the pressures that their managers receive from external forces, such as lobbyist groups from the private sectors and/or politicians who have been 
co-opted to influence the decision into the favorable direction of their supporters.

The same observation was made by an employee of Health Canada, when he blew the whistle on Health Canada's decision to approve the hormonal drug, Revalor- $\mathrm{H}$, as noted in this whistleblower's book, ${ }^{4}$ the manufacturer of this drug, Hoeschst, proposed the use of this drug to improve feed efficiency with the goal of increasing weight gain in female beef cattle (Chopra, 2009: 72-74). However, Chopra and his colleagues found that the drug had undesired side effects to the organs of young female cows and neutered male calves. Despite the concerns expressed by these scientists, his manager wanted to approve the drugs and exerted pressure on the scientists to pass the drug in their assessment of its risk. To Chopra's superior, the side effects on the organs of these animals were irrelevant since the animals would be slaughtered eventually. Chopra was outraged at this response. To him, the effects of the hormone would eventually be transferred to the human food chain and the inconsideration that his superior gave to this issue was a violation of the Food and Drugs Act that directs his department's service to the Canadian public. Chopra provided this as the evidence that "Health Canada views the industry rather than the Canadian public as the department's client" (Chopra, 2009: 162).

Unlike Chopra, Irene believes in changing system from within. She has brought her concerns through the internal disclosure channels that the Canadian public service has set up for employees to report the wrongdoings that they observe in the workplace. Although

\footnotetext{
${ }^{4}$ In 2009, Chopra published a biography in which he chronicled the corruptions that he observed during his employment with Health Canada.
} 
she never shares her concerns with the media, she is nevertheless considered a whistleblower - an internal whistleblower.

\section{From Reluctant Dissenters to Persistent Resisters}

The Gadfly makes the distinction between internal and external whistleblowers. The external whistleblowers bring their struggles into the public sphere by working with the media, non-governmental organizations advocating for whistleblowing, and other discussion forums such as Facebook, blogging, activist websites, while the internal whistleblowers use the internal disclosure processes to bring the wrongdoings to the attention of higher authorities in their organizations. However, internal and external whistleblowers are not segregated groups. One first becomes an internal whistleblower and then may eventually reaches the point where s/he decides to become an external whistleblower. Where the whistleblowing journey starts and ends is dependent on the results of a negotiated process between the whistleblowers and their interlocutors. It is for this reason that Rothchild and Miethe $(1999$, p. 119) refer to whistleblowers as "reluctant dissenters" who are moved by "a tide of events over which they feel they have little control". Through this process, employees move from the position of "reluctant dissenters" (Rothchild and Miethe, 1999) who refuse to comply with orders from their managers, to that of "persistent ethical resisters" (ibid) who put their careers at risk to bring attention of higher authorities in their organization or the public to wrongdoings on ethical ground.

One of the factors that create the persistency that eventually transforms dissenters into ethical resisters is the marginalization that escalates as these employees bring their dissent 
to higher authorities in the public service. The process of negotiations between the state and the whistleblowers usually takes several years to come to a conclusion. After being marginalized for years, these individuals enter a phase of existence that is described best by the term coined by Victor Turner (1969), "liminality". Turner (1969: 95) describes individuals with this experience as "being in neither here nor there, they are betwixt and between the positions assigned and arrayed by law, custom, convention, and ceremonial." In the context of this discussion, the marginalized employees are neither part of the system, nor outside of the system. By expressing their dissent through the internal disclosure process, they have stepped outside the operational norms of their organizations, but still must follow their obligations as employees of the organization. At the peak of their negotiations with their immediate superiors, many informants must go to work even though they are excluded from the actual operations of the organization. This exclusion includes meetings, email correspondences, sharing of files, as well as the actual work for which they have been hired. The phrase, "s/he has been put on special projects," is commonly understood by public servants as the person in question has been removed from the job that $\mathrm{s}$ /he is doing but has been not fired or laid off. While the informants who were marginalized through this approach still receive their salary, they feel an extreme sense of injustice because they recognize this special treatment as a form of punishment for speaking out against authority.

Many become depressed and angry because they are not allowed to do the job that they have been hired to do. They are part of the organization, but they are not allowed to participate in the operations. While they can and must come to their work cubicles every day, they cannot be part of the discussions and the decisions making processes that are 
available to their colleagues. This phenomenon provides the conditions that are conducive for the emergence of the spontaneous communitas, the comradeship that allows an individual to feel accepted and equal to another person, that allowed some whistleblowers to come together to form the Gadfly. The following discussion describes the tactics and practices that the Canadian state has put in place to address disclosures of wrongdoings. I place emphasis on the features of the negotiation process that ended up moving a group of Canadian public servants from the position of reluctant dissenters to the margins of the organizations where they become the persistent ethic resisters who eventually came together to form the mobilized collective called the Gadfly.

The following story of Albert, a former employee of the Canadian public service as well as the founder of The Gadfly, provides an overture for the whistleblowing journey of Gadfly members. In 1994, as Albert told me in an interview, he had concerns about the contracting practices of the organization in which "documents were back-dated; contracts were issued with no financial authority, no preliminary analysis and no legal review; information in contract files was falsified; and commissions were paid for work that was not performed." (personal communication, November 9, 2010) Albert expressed these concerns to his superiors; furthermore, he refused to sign contracts that he felt were in violation of the normal regulations. In 1995, during an internal evaluation of the organization, Albert made several statements that led to the recommendation of an internal audit which investigated the suggestions of financial corruptions that were linked to political ties within his organization. Albert's actions led him to be declared as 'surplus' in 1996. The term 'surplus', used in this context, meant that Albert was no longer needed 
for the operations of his organization. The implicit meaning of the term 'surplus' is almost equivalent to the use of the phrase "being put on special projects"; both of these expressions refer to the act of giving individuals who are not desired by their managers, and who are not no longer permitted to do the job that they have been hired to do. Even though, Albert's actions resulted in an internal evaluation, he was not protected against the reprisals from his managers. ${ }^{5}$

After several years of being the victim of reprisals for speaking out against these practices, Albert's ordeal ended in 1998 when he was reassigned to a new position and offered an apology letter. Five years later, Albert participated in the Gomery's investigation of the Sponsorship Scandal. ${ }^{6}$ Albert retired shortly afterwards - four years before he reached the required age to receive the full pension plan for public servants. The Gomery report established the connection between whistleblowers and management corruption by calling for protection through legislation. The connection was further politicized by the Conservative party's use of Albert's story in its political campaign during the next federal elections. This was seen as part of the Conservative campaign to

\footnotetext{
${ }^{5}$ The current internal process has been criticized for its failures to protect employees who use this process to report wrongdoings within their organization. How the process fails to provide the protection is discussed in further details later in this section.

${ }^{6}$ The Gomery commission was launched to investigate the misuse of public funding in the Sponsorship program of the federal government that was then led by the Liberal party. The commission was created to further investigate the findings in the Auditor General's 2004 report on the program and to provide recommendations on how to prevent the recurrence of corruptions, such as the Sponsorship Scandal, in the Canadian public service. The Gomery commission produced its first report in 2005 to reveal the persons and actions involved in the Sponsorship Scandal, and its second report in 2006 on necessary measure to prevent corruptions of the same nature. A more detailed discussion on the impacts of the Sponsorship Scandal and the Gomery commission on the whistleblowing landscape will be covered in Chapter Four of this thesis (Commission of Inquiry into the Sponsorship Program and Advertising Activities, 2005 \& 2006).
} 
change the public service towards "accountability" and "transparency" in the 2006 election - the platform that they used to remove the Liberal government from its seat of power.

During the 2006 electoral campaign, Albert engaged in some public activities revolving around whistleblowing and politics. As a result, other whistleblowers, or people who were considering whistleblowing, started to approach him. By mid-2006, Albert began to harness the dynamics of whistleblowers in the Ottawa region - an act that led to the creation of The Gadfly. The meetings that resulted from Albert's interactions with these whistleblowers became the first moments of spontaneous communitas in which whistleblowers in liminal existence come together as comrades. Albert's whistleblowing on the Sponsorship Scandal became an important symbol for The Gadfly. To many members, Albert is widely recognized in the public sphere through the developments that are linked to the Sponsorship Scandal, and thus, he has become the publicly recognized voice of authority on whistleblowing, accountability and transparency. Therefore, Albert's role as a whistleblower continues, but the arena in which he attempts to expose wrongdoings is no longer based on his individual ethical platform, but is now based on the collective ethical platform of an organization seeking to speak for all whistleblowers in Canada. Started as a reluctant dissenter, Albert has now become a persistent ethical resister. 


\section{Internal to External Whistleblowing - A Process}

Out of the ten whistleblowers that I interviewed, six were internal whistleblowers and four were external whistleblowers. However, all identified with the experiences of being internal whistleblowers. Regardless of the nature of the issue and the background of the whistleblowers, those included in this research believed that by bringing attention to the right people, they would be able to fix the problem and continue to work in the same place. They all thought that they were only doing their jobs by bringing attention to actions that were not consistent with the principles that governed the mandates of their department and those of the Canadian public service at large. None of them thought that by choosing to address the issue, they would embark on a whistleblowing journey. Being labeled as a 'whistleblower' is undesired, because of the social marginalization that is associated with this terminology. Uys' statement holds true for many organizations: "The organization sees whistle-blowing as betraying of the interests of the organization, violating the rules of hierarchy, bypassing authority, squealing, damaging the reputation of the organization, acting in a hostile manner toward the organization, poisoning the atmosphere, and supplanting cooperation with suspicion" (Uys, 2008: 906, citing BenYehuda, 2001). Furthermore, all the whistleblowers involved in this research use the internal disclosure system because the government promises protection to those who disclose wrongdoings in the public service through the internal channel; this statutory protection is taken away when the whistleblower goes outside of this channel. The PSIC describes the reporting structure of this internal channel:

a disclosure made by a public servant of any information that he or she believes could show that a wrongdoing was committed or is about to be committed in the federal public sector, or that could show that the public servant has been asked to 
commit a wrongdoing.... A disclosure is protected if it is made in good faith to the public servant's supervisor, to his/her organization's designated Senior Officer for internal disclosure, or to the Office of the Public Sector Integrity Commissioner of Canada.... A protected disclosure also includes information provided in the course of a parliamentary proceeding or a procedure established under any other Act of Parliament, as well as when a public servant is lawfully required to make a disclosure (OPSIC, n.d.).

Drawing their immediate managers' attention to the issue was the first action that most whistleblowers took. In situations where the manager chose not to address the concern and dismissed the employee who brought the issue(s) forward, the employee eventually reached a saturation point when s/he could no longer accept the manager's decision and resorted to disclose the information to others in hope of getting the issue resolved. In all cases considered in this research, rather than taking the employee's position seriously and working with them to resolve the issues of concerns to the employees, managers either threatened the employees into compliance with status quo or dismissed the employees as an annoyance.

The next step of the internal disclosure channel requires that the employees bring their concerns to governmental offices dedicated to address the irresolvable issues. The names associated with these offices are: Values and Ethics, Ombudsman, Internal Disclosure, Internal Audit, etc. However, most informants who used these offices felt not only that they did not receive the help that they were hoping to get, but also that by going to them they had triggered reprisals from their managers because their anonymities were not protected. While these offices offered anonymity, the specificity of the issues allowed the managers to easily trace the complaint back to their employees when these offices discussed the issues in question with the managers in the hope to resolve the concerns of 
the employees. In addition, since most employees would have discussed their disagreements on the same issues with their managers before approaching these offices, the managers would recognize that the issues had been brought up with them previously by the employees, and thus, could easily figure out who had brought the issues to these offices. These conditions do not allow for a complete anonymity to be maintained throughout the process of internal disclosure.

When first confronted with his manager's dismissal of the illegality of the contract work for the Sponsorship program, Albert provided 8 inches worth of papers, only $25 \%$ of the information he had accumulated as evidence of the wrongdoing, to the Internal Audit office of his department. He then refused to share the other $75 \%$ of his documentation to the Internal Audit office because he felt that they did not protect him from the reprisals of his manager. As Albert recalled: "[they] were to protect me. They ignored their promise and disappeared. And on the advice of the union, it was...well; 'they weren't going to protect you. Don't give them any information.' So I just shut down and would not give them anymore information and I just had tons" (personal communication, November 7 , 2010).

In 2002, the Auditor General requested that any federal employee who knew about any corruption in the Sponsorship Scandal to come forward and disclose their knowledge to the Auditor General's office. Albert again went to the Internal Ethics office of his department to see if he could respond to the request. However, the Internal Ethics office was a new entity and was part of the Internal Auditors' office that did not protect Albert when he first approached them for help. The response of the Internal Ethics office was: 
"We have to talk about it. You have to show us the documents" (personal communication, November 7, 2010). Albert responded: "No thanks! We know what happened the first time" (ibid). Albert reflected on his decision: "And I really thought that it was naive of them. Or they thought that I was naive and stupid, if they thought that I was going to show them the documents that were still in my possession when they have got me to hang out there to dry, and see if I get fired and didn't give a damn about me. So if they don't care about me... and they screwed me the first time, why should I trust them the second time? There was no way I'm gonna deal with them" (ibid).

Such feelings of disappointment, frustration, and distrust towards these offices are shared among most whistleblowers that I interviewed for the research, with the exception of one. In this exceptional case, the informants found the employees at the department's internal disclosure offices to be very helpful. However, the usefulness of these offices is not in offering protection, but in providing the informants with the access to employees of the department who are familiar enough with the organization to engage in meaningful conversations about their concerns. In this case, the office was also able to offer advice on different options available to the employees. However, it was up to the employees to choose which path to take. In addition, although these informants supported and appreciated the service of this office, they were still subjected to the reprisals as a result of the indirect exposure of their identity.

By this stage, as Albert's story had alluded to, many whistleblowers would discover that the official promise of protection for internal disclosures did not mean that there would not be any consequences. Most people who used the internal system suffered from direct 
or indirect reprisals which could be any combination of the below list which was complied by the Gadfly in a document:

Workplace bullying; Ostracizing; Removal of work responsibilities or authority; Loss of promotion opportunities; Manufactured poor performance reports; Demotion; Threats; Suspension; Firing or constructive dismissal; Blacklisting. Action may also be taken against a spouse or children. Efforts are usually made by those implicated in the whistle blowing to mitigate the damage. These actions can include: Flawed and non-independent inquiries; Attempts to characterize the whistleblower as a liar, unreasonable or unstable, not in a position to know all the facts; Destruction of evidence; Creation of false or post-dated documents; Collusion with other implicated individuals; Intimidation of other employees to prevent further whistle blowing.

Despite the reprisals that they received, most of whistleblowers still believed that their concerns could still be addressed, if they would just reach the right people with the right authority. Rothschild and Miethe (1999: 199) consider this characteristic prototypical of whistleblowers and give it the name, "organizational naïve". The naivety being referred to is the belief that managers within their organizations would be grateful for information that would lead to better alignment between its practices and its mandate or vision. A strong link exists between being organizational naïve and being loyal to ideals of the organization and of the self. Many of the whistleblowers believed so strongly in their ideals of the organization and of society that they naively did not expect that bringing attention to acts that conflict with those ideals would bring negative consequences to their personal lives. A number of individuals did expect some negativity, but even these individuals were not prepared for the consequences and impacts.

During the course of my fieldwork, many of the Gadfly's members passionately demonstrated how their whistleblowing was consistent with their organizational values and expressed disbelief that reprisals had been brought against them for doing their jobs. 
During an interview, a spouse of an informant talked about the loss of her spouse's naivety (personal communication, January 29, 2011):

Whistleblower: "Now I'm no longer innocent?"

Spouse: "...And that was the sad thing. You know that they sort of opened his eyes to the cruelty of the world. And, no, but that changed you."

Whistleblower: "Ah ha, but you're still with me. Couldn't have been that bad." Spouse: "No, but I mean...that changed you."

Whistleblower: "Uh, huh."

Spouse: "And I think that was too bad."

Whistleblower: "Because I should have remained innocent?"

Spouse: "No, but I mean, so few people are."

Whistleblower: "Uh, huh".

Researcher: "What do you mean by innocent?"

Spouse: "Always give people benefits of the doubts. Believing what anybody tells you. And being willing to offer your time, and your knowledge and so on to anybody who needs it and hmm... it sort of like children are innocent, the parents and grandparents will tell them the tallest tales, and they fall for it...because they don't know any better, in a way they want to believe you. It's not stupidity, it's just that they want to believe you."

Researcher: "The goodness in the world?"

Spouse: "Yes."

Researcher: "and you lost that by now?" (addressed to the whistleblower)

Spouse: "well, some of it." (responded to the question to indicate her belief of how the experience has changed the whistleblower).

It was with the same organizational naivety that public servants, who found themselves stranded in the storms of reprisals by following the route of internal disclosure, looked to the OPSIC as their lighthouse. However, those who used this internal disclosure mechanism were just as frustrated with its inefficiency as they were with those in their own departments. What is even more significant is that most people who confided in this office, reported walking out with the feeling that they were the ones with the problems, and that the issues were non-issues; this is rather a pervasive feeling. The employees were not told that they were wrong, but that their issues did not meet the criteria that would allow OPSIC to get involved. This further diminished their trust in the internal disclosure channels. 
Without any help from the system, informants reached out to their unions. The support that the unions provide in these situations varies depending on the circumstance. The union looks at how far the conflicts between the employees and the employers have escalated, and the nature of the conflict. If the main issues are about violation of the employees' rights according to the collective agreements with the public service, then the unions play a more active role in trying to protective the rights of the employee. These cases involve clear acts of threats, harassment, and bullying. In these situations, the support that the unions give include: attending meetings between the employees and their managers, informing the employees of his or her rights, and providing legal support which ranges from advice to the service of legal aids and lawyers. However, despite these services, there are other reports from employees who did not find their experience with the union to be a positive one. The Gadfly members believe this to be because unions are primarily concerned with issues of pay and collective agreements. In their opinions, unions do not truly understand the importance of workers' rights with respect to being able to speak out. When asked about his perspective on the union, an informant offered the following advice:

To me, unions should be in charge on the dissent and whistleblowing issues. They should be taking this up ... because the effect of reprisals on whistleblowers or any bullying is felt through the union membership. Members received the message that it is not safe to speak out and act in anyway that does not satisfy the person $\mathrm{X}$ or $\mathrm{Y}$ when they see another member suffer from reprisals. (The union) cares more about the 1-2 pay increments. Studies have shown that people are more motivated by job satisfaction than money. Unions should be paying attention to real life significance to workers (personal communication, September 18, 2010).

By the time the union was involved, these employees had exhausted most internal channels that were readily accessible to them. They brought in the union not only to find out their rights, but also to ensure that they had access to an entity that was mandated to 
protect such rights. However, all the informants in this research were disappointed with the support that their unions offered to them.

In most of the whistleblowing cases examined in this research, the last step involved writing to the Minister of the department the employee worked for. For many whistleblowers, this was their last attempt to resolve the issue from within the system. Many eventually brought the issue into the public sphere when they were not addressed adequately through the Minister's office. While some cases are still in development, and therefore it is not yet clear whether the whistleblowers would use the external disclosure channel, there is one case that is unlikely to go down the path of external whistleblowing. There is one case in which two informants (who are colleagues) did not go public after their efforts in communicating the issues to the Minister proved useless; instead, they wrote letters to a higher authority in the Canadian governance system urging this office to address the issues while indicating that unless efforts to resolve these issues were to be seen from the department, they (the informants) would be forced to bring the issue into the public sphere. In response to this action, this office sent them a letter asking them to work with their managers to improve the situations. Until this day, these informants have not gone public with their concerns because they believe that visible efforts to address their concerns have been taken. The informants believe that measures have been taken to resolve the issue because a professional mediator was hired to develop a formal contract of operational understanding between these internal whistleblowers and the organization.

However, in the majority of cases, the next step for most employees would be to reach out to the Members of Parliament (MPs) in their ridings to seek political leverage with the 
hope of increasing the importance of the issue. These last two steps are perhaps the real boundaries that distinguish between internal and external whistleblowers. This last action usually occurs after the physical removal of the employees away from the managers and the rest of their colleagues. The employees are usually moved to lower floors, into corners, and into spaces where there are no windows and with tighter working space. In Bob's case, after he blew the whistle to a higher authority in the organization about his manager's disregard for the Official Language Act, he was moved into a much smaller office without any window and away from all of his colleagues. He also did not have access to a computer, which made it impossible for Bob to carry out his normal duties. This is a symbolic act of pushing the unwanted citizens into the margins of society where they are to be deprived of the privilege enjoyed by well behaving members of the group. The public administration system prefers to keep its business away from the political arena as much as possible. By involving MPs into their contestation with the organization, the whistleblower is forcing the politicization of the issues and enabling the entrance of new actors whose agency adds more complexity to the field of power over which the system would like to maintain its' domination. It is at this turning point that the 'reluctant dissenter' becomes the 'persistent resister'. Once they reach this point, they have already become marginalized completely from their organization. 


\section{Marginalization of the Reluctant Dissenters}

The marginalization of whistleblowers takes place through various forms. Examples given by informants include: exclusion from meetings and correspondences, being labeled by peers and management as employees with personality problems, bad performance reviews, supervision of the employee becomes much more restrictive than the norms, and eventually the normal duties are taken away to be replaced by 'special projects'. One of the most detrimental acts of marginalization experienced by all whistleblowers is what they call "mobbing." It is the least recognized and yet it is one of the worst stressor at the workplace due to its nature:

It is an impassioned, collective campaign by co-workers to exclude, punish, and humiliate a targeted worker. Initiated most often by a person in a position of power or influence, mobbing is a desperate urge to crush and eliminate the target. The urge travels through the workplace like a virus, infecting one person after another. The target comes to be viewed as absolutely abhorrent, with no redeeming qualities, outside the circle of acceptance and respectability, deserving only of contempt. As the campaign proceeds, a steadily larger range of hostile ploys and communications comes to be seen as legitimate (Westhues, 2002: 32).

Bullying is also another form of marginalization that slowly becomes corrosive to the overall wellbeing of the whistle blower. Depression and its side effects, including physical illnesses, are experienced by all the whistleblowers that I have encountered. Albert recalled:

I was on stress medication because I couldn't sleep at nights. I was going to work with a blinding headache everyday. Oh, it was bad, but I had to get through the day. Everyday expected an ordeal, but I got through. But when I testified in Parliament, one thing they said was that we all carried the scar, some of us were more visible than others. It's like when you get depressed...there's a definite time when you go through...you know, why couldn't it be somebody else? Then it's like why me? And there's depression. It's a cycle... and some people get locked in the cycle, they never come out. But you will move through acceptance and then looking to the future. But the scar that remains. In the last 10 years of my job, occasionally, the director would ask to see me. And immediately, the first thing 
that went to my mind was: what have I done wrong. I had done nothing wrong. In every case, I knew exactly why they had wanted to see me and it wasn't anything I had done wrong. But immediately the first thought and the reaction, your stress level went straight up and then they came right back down. But the reaction is so embedded in you. You can't eliminate it. So the thought is always there, hidden even from you, until something triggers it (personal communication, November 7 , 2010).

The emotional and/or physical pains often leads to a spectrum of reactions that range from the inability to work to the most extreme case of suicidal thoughts. These struggles often become the ground on which managers use to evaluate the whistleblowers' capacity to perform their duties during this period. Many informants exhausted their sick leaves in order to deal with the physical illness, depression and stress that resulted from the marginalization. Their managers often used these absences as evidence of the informants' incompetency or failure to in meet performance standards.

The emotional traumas also put incredible strains on the personal lives of the whistleblowers. The burden of supporting the family was suddenly placed upon the shoulders of their spouses. In some cases where the whistleblowing remained in the internal disclosure process, the whistleblowers continued to be employed by the public service, and therefore did not place the financial burden on the family. However, these individuals still experienced the emotional and mental traumas and exhaustion described above. In other cases, the informants took sick leaves without pay or decided to leave the public service before they could receive the full pension plans. The spouses of these informants had to deal with the emotional as well as the financial burdens. The strain on the personal lives of whistleblowers is worse in cases involving wrongdoings that were systemic where the threats were not clear or acute. The spouses found it to be extremely 
difficult to understand why their partners would risk their careers and the well being of the families for a cause that did not make sense to them. On the other hand, a number of whistleblowers expressed tremendous gratitude towards their spouses for standing by them through the struggles.

Spouses play an important role in the whistleblower's experience, although the role varies based on the circumstances. In Bob's case, his spouse also works for the Canadian government, shares the same professional networks, and is also a French Canadian who is very passionate about the implementation of the Official Language Act. She was one of the two spouses that I interviewed for this research, and her knowledge of the developments of her husband's case demonstrated that while her presence was not evident in any of the public information that her husband had released on the case, she had been one of the major influences on the developments of his story. In another case, the internal whistleblowers are colleagues and therefore, they find support and comfort from one another. It is not only that they understand each other's perspective by living through the developments together, but they can also take leverage in the fact that, together, they make up two employees with the same concerns that need to be addressed. Their experiences of using this approach over that last nine years demonstrate that it is effective, since their management does show more carefulness and cooperation with them than in other cases. However, sharing a professional environment is not the only determinant factor, Albert who did not work with his wife acknowledged the importance of his wife's support in his whistleblowing journey:

I was unique. And I make the comment very unique in the sense that I have a wife who has backed me up 100\%. And that meant that if they ended up firing me, she would accept that I'd get fired standing of the ground of principle, which was a 
scaring thing when you considered that we had a mortgage and young kids (16 and 18) at the time. They were finishing up high school. We had the mortgage; we had the university in front of us. So the risk, everything is on the line. But what I had at the home front was someone who said: it's alright, I understand, go for it....And to have that type of support is one of the healthiest things that could have happened to us (personal communication, November 7, 2010)

With and without the support from their families, the marginalization from the efforts of trying to blow the whistle through internal disclosure channels led to the intense feeling of despair and helplessness that eventually drove most of the internal whistleblowers into the public sphere to seek support. They feel 'betwixt and between': loyal to what they see as the principles of their organizations and yet they were being punished for it. These employees enter a liminal phase through their experiences of being pushed outside of the boundaries of the dominant social structures of their organizations. In liminality, they become part of a larger group of people who embrace the act of whistleblowing and the elimination of the marginalization against them. Internet and social networks are the most common resources that lead people to advocacy networks of organizations such as the Gadfly. Most of the whistleblowers I interviewed were founding members of The Gadfly; however, there were a few people who discovered The Gadfly through Internet searches and became involved as the result of their subsequent interactions with the organization. They approached The Gadfly to seek advice on what other venues were available to them since they had reached the end of the internal disclosure channels without any success in resolving the issues that first set them down this path. These individuals are faced with few options: take legal actions against the government, drop the fight and silently look for another job or a change of career, or go to the media with their concerns. 


\section{Struggles of Persistent Ethical Resisters}

As of 2003, the litigation option was no longer available to public servants. In 2003, the government put in place the Modernization Act, which prevents public servants from suing their employer. However, even before the Act came into force, most whistleblowers told me that they dreaded the thought of engaging in a litigation process which would take the government to court. Most do not consider this choice unless they have the financial support from their unions; even then some expenses are to be absorbed by the whistleblowers. As the result, many whistleblowers chose to settle with the government after several years of struggles.

The settlements usually take the form of disability retirement or early retirement that would allow the employee to receive a certain percentage of their regular income with the condition that the employee would not hold a full time job while they received the pension. Three out of the eleven informants that I interviewed chose disability retirement. Two other whistleblowers chose early retirement. The retirement pension is calculated using the following formulation: $2 \% \mathrm{x}$ Number of Years of Pensionable Service $\mathrm{x}$ Average Salary of 5 Consecutive Years of Highest Paid Service (Treasury Board of Canada Secretariat, June 3, 2011). Since the amount of received pension is dependent on the years of service and the highest salary level that an employee reaches in her/is career, employees who choose early retirement take a significant reduction in their retirement fund. To receive the full retirement pension, the employees must either retire at the age of 60 or older and have served in the public service for at least two years, or retire at the age of 55 or older and have served in the public service for 30 years (ibid). The implication of 
retirement before reaching these criteria means that the employee's annual income decreases while the financial burdens of their personal lives still remain.

At the time of retirement, the two people who chose this route still had dependent children, mortgages, etc. Bob, who blew the whistle back in the 1980 s, received a much harsher treatment - he was fired for insubordination. With this, he lost the government's contribution to his pension plan. The Canadian public service contributes $60 \%$ of the cost for its employees' pension plans (ibid). In addition, he would not receive unemployment insurance until five weeks after the termination of his employment because he was fired from his position. This is a condition that Service Canada imposes on workers who are fired from the service (Service Canada, n.d.). Bob's reprisal was the most extreme of all the whistleblowing situations that I explored for the research. It was also one of the oldest cases. Nowadays, managers in the public service are more careful in their responses to employees who use the internal disclosure processes. However, while firing has not been a common practice in the public service, the implicit threats to career developments are still be made against these organizational dissenters.

Beyond the reduction of income, whistleblowing also has a detrimental impact on the employment prospect of the whistleblowers. All of the informants, including those who have only reached the early stages of internal disclosure, believe that they have been 'blacklisted' from getting another job in the public service. Most people found out about the blacklisting through their social networks or concemed friends who advised them to be more careful with their careers. Many only discovered the reality of blacklisting after their many failed attempts of trying to find a different job somewhere else in the 
government. And some were informed of their membership into the 'blacklist' before they even made the attempt to change jobs. Therefore, even if the employees gave up the struggles after not being able to use the internal disclosure system to address their concerns and quietly seek for another job, their actions thus far would have already stigmatized them as a "troublemaker". As a result, they would have difficulty trying to build a career in another place within the public service. Because of this, the majority of whistleblowers involved in this research stayed in their job for as long as they could until they chose early retirement, while some decided to restart their careers with other departments in the public service and accepted the set back.

\section{Conclusion}

Whistleblowers are often accused of being disloyal to their employers. The findings of this research support the reconceptualization of loyalty that Uys (2008) proposes as a way to understand the underlining motivation of some individuals who choose the path of whistleblowing. This form of loyalty - rational loyalty - is grounded in these individuals' beliefs in their personal ideals and those of their organizations. They translate the principles behind the words that their organizations profess through their own knowledge, experiences and ethics as individuals. The informants of this research perceive the corruption of their organizations based on what they view as systematic practices that are currently considered as the norms in their organizations As such, their dissent to such institutional corruption are not often supported by their colleagues who either do not share the same perception of wrongness or do not want to put themselves at risk for going against the dominant norms of the organization. When the translation differs from the 
organization's norms, rather than letting go of their individual positions, whistleblowers are motivated by their loyalty to what they see as the ideals of the organization which leads to dissent against some orders from their superiors. They become the reluctant dissenters who hope to find support and understanding from higher authorities in the public service by following the internal disclosure processes that are legislated by the PSDPA. However, rather than being protected by the Act, whistleblowers of the Canadian public service find themselves being subjected to retaliations and penalization for their actions. The retaliations from employers and the related impact on the whistleblowers' economic and social circumstances transforms the whistleblowers' reluctance in dissent into a persistency to resist their organization and the culture that marginalize whistleblowing on the ethical ground.

As they become marginalized for disrupting the organizational culture, they find themselves outside the boundaries of not only the structure of their organization, but of the social structure at large. They exist in ambiguity - not part of the organizational structures to which they once belong, not completely outside of these structures either, and not yet part of any other structure. This liminal existence originates from their professional lives and transcends into other structures that construct the social world of these individuals (family, friends, livelihood, etc.). In this liminal phase of existence, the whistleblowers from my research discovered other whistleblowers that shared similar experiences, and therefore are able to relate to the struggles in dealing with the impacts that whistleblowing has on their lives. This common ground became the basis on which the Gadfly was founded. The next chapter discusses the challenges that The Gadfly has been facing as it tries to formalize its existence as a non-governmental organization. 


\section{Chapter III - CHALLENGES OF IN-ACTION SOLIDARITY: THE GADFLY}

The Gadfly was founded based on the spontaneous communitas that its members experience together as they are pushed outside of their professional institutions for blowing the whistle internally and/or externally. The sense of comradeship has offered many of them the emotional support, the practical support that comes with sharing the whistleblowing experiences with each other, and the solidarity on the issue that the Canadian government to improve whistleblowers' protection. However, the spontaneous communitas has deteriorated as the Gadfly tries to formalize its structure and operations. The internal negotiations on how to manifest the shared vision and political platform for the organization have reached a critical point that triggers many members to wonder if there is a future for the Gadfly.

The Gadfly is trying to bring a social structure into their existence as an organization. They want to develop a structure that is based on shared ideals and that can systematically foster the spontaneous communitas that has brought them together. However, this endeavor has triggered many challenges that results in the Gadfly is experiencing difficulty holding onto to its solidarity and making progress on its objectives and vision for the future. Turner (1969) coins a term for social structures that go through such evolution: normative communitas. He observes that such communitas result from the inevitable need for structure that all spontaneous communitas will eventually develop. However, the formation of the normative communitas also means the denaturing of the spontaneous communitas that serves as the key to the solidarity of the Gadfly's members. In addition, most of the Gadfly's active members are whistleblowers who are still dealing 
with their own whistleblowing cases. As an organization that is transitioning into a structure, the Gadfly is also in liminality. Like the individuals that make up this organization, the Gadfly is neither here or there; The Gadfly is no longer the manifestation of the spontaneous communitas that has fostered its creation, and it does not yet have a structure on which its operations could be based. The liminality existence creates many uncertainties in perspectives and corresponding actions, and thus this factor becomes the barrier to progress towards a specific direction.

Moreover, the Gadfly's members travel back and forth through an action continuum that takes them from being the lonesome whistleblowers to the activists that once belonged to a larger collective. While this action continuum offers the advantages mentioned earlier, it also interferes with the level of engagement that the Gadfly's members could sustain in their respective responsibilities within the Gadfly. Many of its members question whether the Gadfly is at risk of disbandment. However, the challenges that the Gadfly faces in translating the solidarity in principles into the solidarity that exits in actions, also present the organization with the opportunity to create a social structure that reflects transparency and accountability - the very ideals that the organization promotes.

The first section in this chapter discusses the challenges that are associated with the different aspects of creating and moving into a structured existence. The challenges are related to operational space, required funding and the support that the Gadfly can provide to whistleblowers. The second section describes the challenges and the advantages of moving back and forth in an action continuum between whistleblowing and mobilization. Together these sections analyze the internal workings of The Gadfly during this 
transitional phase as it swings between existing as a self-help group of whistleblowers, and an institutionalized non-governmental association of persistent ethical resisters.

\section{Challenges with Moving into a Structured Existence}

The Gadfly provides direct and indirect support for whistleblowers. Direct support for whistleblowers is given through various forms: the organization of dinner meetings that take place every two weeks (this support has evolved to another format - further discussion on the transformation will follow); provision of advice to individuals who seek support from the organization; maintenance of The Gadfly website and Facebook account that provide information on national and international developments with respect to areas that would affect whistleblowing, such as news on the Canadian Public Service Integrity Commissioner Office, Canadian Public Servant Disclosure Protection Act, Transparency International, and WikiLeaks. as well as the self-help tools that have been developed throughout the world to help whistleblowers.

The operation of the Gadfly relies mostly on the efforts of its ten directors and the president. There is not much active involvement from other members of the organization. Considerable efforts have also been made by some directors to provide indirect support for the cause of whistleblowers, through advocacy efforts such as representing whistleblowers in formal conversations with politicians, bureaucrats who are responsible for the institutionalization of ethics and accountability for the Canadian public service, the media, and other NGOs who share a similar advocacy cause as The Gadfly. These activities make up only a small part of what the organization has envisioned for itself in 
2009. Before then, activities of the organization existed out of needs that arose when interested individuals contacted the organization or its members as they became aware of The Gadfly.

In 2009, the directors of The Gadfly wanted to develop a business plan in order to better focus their activities and improve their chances of success in supporting and advocating on behalf of whistleblowers. The following activities were included in The Gadfly's business plan that was dated for November 2009:

(1). Whistleblower support which include offering "an open ear", "analyze the case from a neutral perspective", "help put the situation on paper", "let the individual know what her rights are", "advice on possible courses of action within an organization", "advise on whether a lawyer should be consulted", "accompany you to sensitive meetings assistance in preparing "Access to Information" requests connection to other whistleblowers in similar situations", "help write letter write to persons in authority to lend support to a cause";

(2). Case Management;

(3). Case files: primary case analysis;

(4). Support Organizations: Workshops: how to support whistleblowers, train the trainers, presentation and training on whistle blowing, presentations and training on a healthy workplace, presentations and training on ethics, policy advice;

(5). Course and Presentation: how not to be a victim, healing, ATIP;

(6). Marketing: communication, radio and television, collaboration with universities;

(7). Funding 
This business plan remains a draft. Since then, the Gadfly leadership has been going through endless hours debating with each other on what type of activities are to be carried out by the organization and how the activities should be operationalized. These debates take place mostly in the bi-monthly meetings and emails between members of the Board of Director. As a result, there are numerous versions of such a visioning document; however, the final decision has not yet been made. At present, the activities, that are currently taking place within The Gadfly, represent only a small part of what the organization had envisioned in November 2009. Nonetheless, The Gadfly is still experiencing many difficulties in its operations. Differences on how to put in practices the vision for the organization has occurred in all aspects of its operations: the space where its activities take place, the sources of funding required for its sustainability, and the type of supports that it can offer to the common cause of whistleblowers' protection and accountability.

\section{Dinner Meetings - The Transition into Structure}

Throughout its struggles to establish an operational framework, there is one central element of The Gadfly's mandate that has consistent and unanimous consensus from all members: the 'grassroots support'. In this context, the Gadfly's members use the term 'grassroots support' to describe forums that the organization creates in order to facilitate the whistleblower-to-whistleblower support dynamics. The Gadfly considers this grassroots support as the unique feature that sets the organization apart from other Canadian advocates for whistleblowing. For many active members of The Gadfly, it is the promise of this grassroots support that motivates them to be part of the organization. 
This grassroots support has being going through many transformations. Its earliest form took the shape of dinner meetings where information of what to expect throughout the different stages of the whistleblowing experience was shared. These meetings started as individual discussions between the founder of the Gadfly, Albert, and other whistleblowers who approached him for advice on how to deal with their situations. The dinner meetings went from one-on-one, to small group gatherings, through Albert's efforts to build connections between whistleblowers. The spontaneous communitas felt during the one-on-one interactions between Albert and other whistleblowers was also established among other whistleblowers as more people became aware of each other through their individual social networks. These individuals provided each other with the sense of comradeship not only through their understanding of the commonalities between their individual whistleblowing experiences but also in how they were relating to each other. On one occasion, a Gadfly member gave the following recommendation to the Gadfly regarding a new whistleblower: “...we should embrace Mr. X as a kindred spirit..." (personal communication, November 23, 2009). This Gadfly member evidently experienced a moment of spontaneous communitas with the new whistleblower. Based on this, he recommended the inclusion of the new whistleblower into the group. The accumulation of similar events gave rise to the emergence of a core group. The discussions among members of this core group during their dinner meetings, eventually led to the decision to form an organization that would extend the support that the dinners were providing to each other to the larger network. Some time in the last decade, The Gadfly was formally created. A year after its creation, it was incorporated as a non-profit organization. 
Until early 2011 , the dinner meetings continued to be held every two weeks and the participation was increasing. Although the number of people at the meetings increased from four to roughly fifteen per meeting, the format of the meeting was not changed to adjust to the expansion of its membership. The meetings took place at a local restaurant where the founding members first met with Albert. The maximum seating available at the biggest table was twelve. As the participation increased, each meeting would involve people pushing up against each other, sitting elbows to elbows, as they tried to carry out conversations and grabbing whatever portion of the food dishes that were spinning around on the table-top turning wheel. Due to this format of dinning, the foci of people were divided between getting enough food to eat and the conversations being tabled - of which there was usually more than one. In addition, the limitation in space forced the waiters and waitresses to squeeze their arms and bodies between and over any tiny space that the dinners were able to make to allow the service staff to clear the table of empty dishes and reload new ones. Since the dinners were full-course meals served in the communal dining format, the frequency of the service staff was very high. This constant traffic became a continual source of conversations disruptions and annoyance for those who wanted undivided attention from the participants at the meetings.

When I first attended these dinners in 2009 , I observed that as people waited for the food to arrive, which could take up to thirty minutes, they were asked to introduce themselves to a group of no more than 10 people who were relatively still new to each other. The introduction was a ritual through which the diners gained trust and informal membership into the world of whistleblowers. This was accomplished by presenting an elevator speech of their experiences with whistleblowing. Empathetic facial expressions and 
gestures would be given to any new member who would usually carefully tell their ordeals without revealing too much information. Everyone walked out of these dinners with a sense of relief that they seemed to have found a community which embraced the very thing that had been alienating them from their former social groups. The desperation that they felt as they moved further and further into the margins of the social acceptance in their workplace and/or family, subsided as they heard about the commonalities of experiences in the stories being shared around the table.

Throughout these meetings, the legitimacy of the whistleblowing situations was never questioned. People did not ask whether the label of corruption/wrongdoing was justified. And details of these stories were not shared among the diners. Hence, the commonalities between the diners were not found in the logics of rights and wrongs, but rather in their shared experiences of the ways in which the government responded to their actions. Therefore, the connections that brought the spontaneous communitas to people, who participate in these meetings, were built on their contempt against the approach that the government took in response to their actions as reluctant dissenters and/or persistent resister. The spontaneous communitas felt by diners in this liminal space forges a certain sense of fellowship. This fellowship is grounded in the understanding that each individual was an ethical person and an abused victim of their employers (the public service in general and the relevant departments in specific).

However, the fellowship within the group can also be established through the commonality on personal ethical principles. There are several people who did not consider themselves as whistleblowers, but they attended these meetings and played 
important roles within the organization. These people would then provide their ethical platforms as reasons for their participation in these meetings. These would include personal interests in fighting corruption or in helping to bring transparency and accountability to the federal government, their solidarity with whistleblowers, or academic interest in the subjects related to whistleblowing. These participants came from academia, private and public sectors. The different rationalities reflect the complexities involved in the definitions of whistleblowing and whistleblowers. The scope of inclusivity in the definition of whistleblowing is important for many reasons, and one of them is the acceptance of an individual into the fellowship established through these meetings. This became evident when individuals, who did not self identify as whistleblowers, were brought into the fellowship through justifications that often involved how the actions of these individuals could qualify as whistleblowing or in support of whistleblowers. These justifications were often provided to the group by people whose memberships in the organization had already been established. These moments, during the meetings, were often accompanied by personal speeches of empowerment by leading members of the group.

This sense of cohesion of the collective, the 'communitas', was vibrant and very much alive when I was first introduced to the organization in 2009 . However, it faded in the last two years as the group tried to become more formalized as an organization with defined infrastructure, funding sources, mandates and the corresponding activities. Between 2010 and early 2011 , when the dinner meetings were still being held by some Gadfly members, the empowerment dynamics still crystallized whenever new people came to the meetings, especially those who had just blown the whistle or those who were struggling with how to 
deal with their dilemmas without blowing the whistle. During my last participation in such a meeting in February 2011, a whistleblower who had travelled from Montreal to Ottawa to participate in this meeting shared with everyone that while she was going through the most difficult phase of her whistleblowing experience, she always had The Gadfly's website opened on her computer screen. The website became the source of strength for her to go on and she took consolation in knowing that there was a group of people out there, behind this website, who understood and were sympathetic to her cause and situation. The group immediately focused their attention on the new woman and provided her with signs of empathy and understanding through their undivided attention, gestures and sympathetic words. The empathetic gestures offered by existing members helped the newcomers to feel less isolated and lonely in their struggles - this effect was shared among all diners. However, the communitas ceased to exist when specific issues regarding the operations and the formalization of the organization became subjects of discussion.

These meetings were partially formal in that, from time to time, informal agendas, discussing how The Gadfly could further establish itself as an organization, would be tabled and discussed during the dinners. When the number of participants had not yet reached ten, the tabled agenda and its corresponding discussions were already experiencing challenges in being able to capture attention of all diners. Even then, side tracked conversations and lengthy discussions about individuals' situations did not allow for the smooth running of the agendas. The constant distractions, the lack of focus within the group's dynamics, the lack of structure of the discussion format, and the awkward combination of the informality of social gatherings and the formality required for 
meetings in which important decisions were to be made, eventually led to individuals' frustration of not being heard and understood. The difficulties of resolving differences in perspectives, knowledge and experiences rose to the surface as the sympathetic talks of fellowship among whistleblowers turned into how the organization should operate. Disagreements were not resolved, but rather accumulated with each meeting. This led to the development of animosity between some individuals who held key functions in the organization, and discouraged whistleblowers, who would come to the dinner meetings to seek support, from continuing their participation in future dinner meetings. The following account describes a development that resulted in numerous emails and phone conversations in which several founding members contemplated resigning from the Board of Directors due to their disagreements with the discussions that took place at the dinner.

During a social meeting in November 2010, a member of The Gadfly, Jack, wanted to share a letter that he had drafted to lobby Members of Parliament (MPs) to support Albert to be considered as a candidate for the currently vacant Integrity Commissioner position. The proposed idea of The Gadfly being the signatory to this letter was shot down multiple times by its former treasurer, Rupert, even before the first line of the letter was read. Rupert questioned who would pay for the letters to go to the MPs. In the past, in another effort to incorporate politicians into their platform, The Gadfly had paid over $\$ 400$ to send out these letters - an expense that Yan, one of the Gadfly's founders, thought superfluous as letters to MPs could be sent at no cost. The next point that Rupert raised was that The Gadfly was not to be the author and could not be referenced in the letter because it would be a conflict of interest. Furthermore, he pointed out that a member of The Gadfly also could not send this letter out, as this would implicate the organization. 
Jack dismissed these concerns by casually threatening that he would resign in order to send the letter as he wished.

At this point, one of The Gadfly's directors voiced his opinion that Rupert was actually making a good point and the idea needed to be considered in the discussion and should not be ignored. This triggered more discussions on who should be the author of the letter. An established academic, who knew Albert from his studies, was nominated by another director of The Gadfly to be the author. This led to a lengthy discussion of who would make good Members of Parliament and quickly turned into a tense exchange between members who were supporting different political parties; those who did not participate in the debate were outwardly annoyed at the turn of the conversation. The debates on political parties were not relevant to the question of whether or not The Gadfly should be connected to the recommendation of a new Integrity Commissioner of OPSIC. This central issue was never resolved to the satisfaction of all members. And the political conversation that was out of context continued to brew tensions throughout the organization as members vented their frustrations through email correspondences. Conversations such as the one described here were common not only at the dinner meetings, but were also observed in the bi-monthly Board of Directors meetings in which The Gadfly's elected directors meet to discuss the operations of the organization.

The spontaneous communitas cannot be maintained for a long period of time because the needs for structure will prevail and the "free relationships between individuals become converted into norm-governed relationships between social personae" (Turner, 1969: 132). The above vignette provides evidence of the social transformation that Turner is referring 
to. The solidarity based on the spontaneous communitas, experienced by founders and early members of the Gadfly, gradually disappears as its members try to operate not as individuals but as members of an organization with a social structure. The form of structure that the Gadfly tries to establish is what Turner calls a "normative communitas" - a "perduring social system" results from the need to organize resources and social control within the group in order to pursue common goals (Turner, 1969: 132).

One of the problems that Turner saw in normative communitas was the "protective institutional armor" that would form in response to these groups' perception of their vulnerability to the institutionalized groups (Turner, 1969: 49). I heard several members of the Gadfly complain that the overall operation of the organization was not holding up to its own motto which is based on transparency and accountability, and that the organization is risking public and governmental scrutiny in this contradiction. However, this is only the peripheral view of the issue. The underlining problem that the Gadfly faces is its existence in liminality as an organization. The liminality is brought about by the transformation from spontaneous to normative communitas. This transformation is challenging for the Gadfly's members in two ways.

The first factor that makes this transformation challenging for the Gadfly's members is the disappearance of the spontaneous communitas that initially brought its members together. This form of communitas cannot be normalized; therefore, it has to be "denatured" as the result of the group moving towards normative communitas (Turner, 1982: 49). The challenge arises in the reliance the Gadfly's members have on this spontaneous communitas in order to relate to each other, for it has been their way of 
seeing the values in fostering the individual and communal relationships between and among members of this group. Therefore, when this form of connection disappears, the members of the Gadfly struggle in their attempts to maintain its essence, in the new form of communitas. It is through this struggle that conflicts, such as those described above, arise.

The second factor that contributes to the challenge is the novelty of this form of social organization, in this specific context, and its relation to its members. The novelty lays in what can be seen as the nature of this form of social organization. Although the spontaneous communitas no longer exists, its members still aspire for the Gadfly to be based on values such as "liberation" or "freedom" which drew them to it, as a way to find solidarity against the work situations that marginalized them. Therefore, the normative communitas is neither the spontaneous communitas that the Gadfly's members just discovered in it nor the dominant form of structure that they have left behind when they became whistleblowers. Neither here nor there, members of the Gadfly struggle to form some kinds of existence as a group based on the structures of the social organizations that they know.

Many members of the Gadfly are also involved in other not-for-profit and nongovernmental organizations that exist as perhaps different models of normative communitas. The personal knowledge and experiences, in formation of groups based on non-dominant structures, are the benefits as well as the liabilities that many members of the Gadfly bring to the group. Each individual has a vision of how a certain shared goal can be achieved, and their personal experiences and knowledge inform their conviction to 
the point that it is difficult for the Gadfly to move forward. Therefore, part of the challenges that the Gadfly faces is the creative process to develop a form of normative communitas, while experiencing liminality.

Similar challenges in transforming the solidarity built on ethical principles to solidarity in actions have been observed in research works on social movements networks and their local actors - non-governmental organizations and activist groups. In a recent study of social movements, Juris describes the members of groups that participate in these movements as "cultural innovators" as they attempt to develop new "models of behavior and social relationships that enter into everyday life" (Juris, 2008: 296, citing Melucci, 1989), and who participate in the global "social laboratories" (Juris, 2008: 297) in which new "cultural practices and political imaginaries" (ibid) are synthesized. The challenges experienced in these social laboratories is part of the 'dual politics' involved in "constituting tactical infrastructures for intervening within dominant political spheres while simultaneously prefiguring alternative, directly democratic worlds" (Judith, 2008: 296). This theoretical lens takes into consideration the transformation of social structures described by Turner, but does not limit the problems experienced in this transformation as a protective response to the threat of institutions. Under this lens, the Gadfly can be seen as 'social laboratory', in that its members are attempting to create a model of social structure that reflects the changes its members are calling for in their individual whistleblowing cases. The experimentations and the challenges that take place in this social laboratory are most dominant in three areas: the form of grassroots support that the Gadfly could offer, funding to support its activities, and space where its activities could take place. 


\section{Funding}

Without much overhead costs, the expenses of the organization are quite limited. Volunteers, mainly directors, usually pay for small expenses of the activities. Major expenses are those associated with meetings, advocacy initiatives, group insurance, and a mobile phone that, for almost a year, served as a channel through which whistleblowers could reach designated directors who had volunteered to help whistleblowers to deal with their specific situations. The Gadfly relies completely on its membership fees and personal donations as funding sources. The membership fee is $\$ 30$ per year. Personal donations come sporadically from individuals who send money directly to the organization, or from the social dinner meetings in which each diner contributed $\$ 20$ to the event (as long as the dinners were being held). After the cost for the dinner was paid, the leftover amount was handed over to the treasurer who made the deposit into an account that was created for the organization. As of January 2011, the organization had roughly around $\$ 1500$ in its account.

In 2009 , the organization wanted to apply for a number of governmental and nongovernmental grants in order to increase its funding - one particular grant of interest to The Gadfly was the Ontario Trillium Foundation. However, as of January 2011, the application was still not made. In order for The Gadfly to be considered for this grant, the organization had to have certified charitable status. Canada Revenue Agency is the governmental agency that is responsible for this certification. The status comes with certain conditions; one of them is that charitable organizations "must not engage in prohibited political activities or unrelated business activities" (Canada Revenue Agency, 
n.d.). Since its conception, some members have been working with the media to raise the profiles of whistleblowers and the organization. Some of its official views have been published in the major media outlets including the Hill Times. Some members interpret these acts as political activities, and therefore question whether continuation of these activities would prevent The Gadfly from being recognized as a charitable organization. The Gadfly members, who advocate the cause through this practice, see these activities as crucial to their mandate, and therefore are not willing to consider dropping these activities from the mandate of the organization.

Similarly, some directors suggested that people who approach the organization for these services should pay The Gadfly for some of its services, such as case management. However, many directors were opposed to this solution, for they believed that such grassroots support should be free. This belief was based on the rationale that most of those who finally gathered enough courage to reach out for help would already have limited resources because of the financial constraints due to their whistleblowing. At the same time, some were also concerned that charging for this service would remove The Gadfly's eligibility as a charitable organization.

Other ideas for sources of funding included providing workshops to governmental bodies who would like to offer training on accountability and transparency to their employees. Several of the Gadfly's directors believed that some organizations would view this training as a measure against the crystallization of external whistleblowers in their organizations - a position that the directors believed would bring mutual benefits to the organizations and their employees. Organizations with the mandates to reduce damages 
from conflicts in the workplace were mentioned as potential clients. OPSIC and some major unions for public servants were named explicitly during these discussions. However, many Gadfly directors are concerned with the latter idea because of conditions that may come with the funding. As a result, The Gadfly directors have been spending a significant amount of time discussing whether some of their activities would be considered as "prohibited activities" and questioning the eligibility of The Gadfly for the Trillium grant. During one of the Board of Directors (BoD) meetings I attended, Albert questioned whether it would be a waste of time for the organization to prepare the funding application when they were still unclear about what they would like to do as an organization.

\section{Space}

The Gadfly's struggle to define itself also manifested through the concept of space. My first invitation to the BoD meeting was in September 2010. The organization did not have an office; therefore the meeting took place in Irene's dining room. Prior to my first formal participation in the $\mathrm{BoD}$ as a researcher, I was invited to participate in a couple of these meetings as a guest. Talks regarding the need for a real meeting space, that of a boardroom, was expressed repeatedly by a few directors - most were not comfortable with holding the meeting in someone's living space. In the Fall 2010, soon after my first meeting, the Board of Directors decided to change the location of these meetings. Several people, including myself, suggested places that were familiar to each of us - none of which was acceptable to all members of the board. However, the discomfort with holding meetings in spaces that were considered as familiar ground for individual members 
eventually led to the choice of renting a room in a local library which seemed to offer the neutrality and amenities that all members had been seeking. The same location is currently being used as the hosting place for monthly meetings for all members of The Gadfly and invited guests. The consensus on the space led to the launch of a new form of grassroots support that had been designed to replace the original social dinners. This new service is called 'Whistle Watcher', and is scheduled to take place during the monthly meetings at the new location.

The format of the Whistle Watcher meetings is similar to other structured self-help groups, such as Alcoholic Anonymous, in which there are at least two people who work together to facilitate the discussion in order to ensure that everyone has the opportunity to speak and to be heard. The participants remain anonymous. During the meeting, only first names of attendees are used in the discussion and names and places are avoided when sharing personal stories with the group. The goal of this process is to enable an exchange of knowledge and experiences in whistleblowing, and to help each other avoid being victims of reprisals, as well as helping each other to bring about the changes that drive people to consider whistleblowing. I only witnessed the birth of this new format of grassroots support for individual whistleblowers, because my fieldwork concluded prior to its first launch. However, my personal correspondence with its architect, Irene, reveals that the meetings have been successful. It would seem that the success that the Whistle Watcher meetings are experiencing is partly due to its ability to re-create the spontaneous communitas that engenders the solidarity among whistleblowers during The Gadfly's early days. However, similar to the earlier dinner meetings, the solidarity experienced 
during theses meetings is limited to this space and has not been able to penetrate the other operational spheres of the Gadfly.

\section{Case Management}

In 2009, the Gadfly decided to create the service called "Case Management" to provide this support for whistleblowers. Out of the ten whistleblowers that participated in this research only one person approached the media to blow the whistle publicly while he was still employed, but this happened only after he had engaged in litigation measures against the government. The option of going to the media and using litigation measures are often the last resorts for the majority of people; certainly, this was the case with the whistleblowers involved in this research. This is not only because the costs, financially and emotionally, are too high, but also because their stories, by this time, have become a web of complicated interactions between themselves and different interlocutors. Many whistleblowers, at this point, would have been in such emotional traumas that they have difficulty presenting their case and the logics of their thinking to another person. The situational awareness and the subject expertise that is required in order to understand the wrongness of the issues being raised creates another challenge for whistleblowers. The difficulty that whistleblowers have in presenting their stories to others is considered as an extremely important reason as to why whistleblowers need external support.

The Case Management was intended to be a whistleblower-to-whistleblower support system. The approach was designed based on the belief that those who have gone through a similar experience would understand the nuances involved in the negotiations between 
the employees and their employers, and moreover, would be familiar with the multifaceted impacts that the whistleblowing experience has on those who approach The Gadfly for support. Through the support systems offered by the Case Management Service whistleblowers move from the position of a lonesome reluctant dissenter to that of a persistent ethical resister who is part of a mobilized community.

The Gadfly planned on providing the following support in their Case Management service: situation analysis by their directors; documentation of the case; information on the basic legality of whistleblowing; advice on how to deal with responses from the workplace of the whistleblower; act as observers in meetings between the whistleblowers and the interlocutors, especially those who represent the interest of their employer (for example: lawyers, Human Resources representative, member of the senior management); assist in preparing Access to Information (ATIP) requests; connection to other whistleblowers in similar situation; support in writing letters to the employers and/or the media, support in writing letters to persons who can be used as leverage to support the cause (The Gadfly Draft Business Plan 2009).

By summer 2010, a Case Management team, composed of four directors (Albert, Irvin, Irene and William) was established. One member was responsible for the management of cases that came into the organization through varying channels: emails, personal referrals, or through a phone line that was dedicated to receiving calls from individuals who approach the organization for help in dealing with the situation that they are facing. The situations were quite diverse - from personal disputes to knowledge of wrongdoings in the workplace. 
Despite the fact that the plan had buy-in from most members on the board of directors, the operationalization of these ideas did not turn out as expected. Due to the overwhelming number of cases and the demanding nature of this service, members of the Case Management team gradually ceased trying to keep up with the workload, until they finally gave up completely in November 2010 when the board of directors decided that case management, in this format, was no longer feasible for the organization. Their failure is due in part by The Gadfly's existence in liminality, as well as their attempt to normalize the sporadic whistleblower-to-whistleblower support that it has been found to be useful in its informal gatherings. Their failure also reflects the challenging role of trying to provide help others while those offering the help are still coping with their own personal whistleblowing issues. While the concept of whistleblower-to-whistleblower support offers many advantages, as discussed earlier, its disadvantage is what one informant called "the blind leading the blind." (personal communication, January 29, 2011). The difficulty is in trying to cope with the challenges that arise from one's own situation as a whistleblower, while attempting to support other whistleblowers to deal with their own cases. Members of the Case Management team, and some of the most active members of the Gadfly, represent the group of the reluctant dissenters whose persistency led them to become ethical resisters, not only in their own situations, but also as the members of the mobilized group of ethical resisters. The challenges that they face in their attempts to deliver the Case Management service highlight important issues that arise in this unique phenomenon.

In his exploration of the potential alliance between whistleblowers and protestors as forms of ethical resistance, De Maria (2008) calls for empirical research to explore the 
connection between whistleblowing and mobilized ethical resistance. In looking at whistleblowers as a form of ethical resisters, he asks: "To what extent is it possible for ethical resisters to move through a social action continuum from whistleblowing to mobilization and perhaps back again? If there is tactical fluidity, what drives this movement?" (De Maria, 2008: 877). The next section shows that a social continuum between whistleblowing and mobilization exists in the Gadfly as some of its members move back and forth between being the whistleblowers and the advocates for whistleblowers' protection. The discussion will also highlight the challenges and the potential drivers of this movement.

\section{Whistleblowing to Mobilization and back}

By looking at whistleblowing as an organization protest, De Maria conceptually constructs whistleblowing and public protests as two points along the ethical resistance continuum in which individuals can go from organizational protest to public protest, from internal to external whistleblowing, and from whistleblowing to either organizational or public protest (2008: 869). De Maria demonstrates that the collaboration between these two groups of ethical resisters, and the blurring of this boundary on the anti-corruption measures, could provide "untapped synergistic potential" (De Maria, 2008: 865). He called for further empirical research that looks at the phenomenon in which the “Monday's whistleblower may be Tuesday's petitioner, Wednesday's rally organizer, Thursday's delegation to management and Friday's media source." (De Maria, 2008: 868). De Maria asks to which extent this movement is possible, and if the tactical fluidity that engenders this movement does exist. If so, what is the driving force. 
The existence of the Gadfly as a grassroots organization which publicly advocates for whistleblowing, while also being founded and led mostly by whistleblowers, provides affirmation that "social action continuum from whistleblowing to mobilization and back" (De Maria, 2008) does exist. However, using the Gadfly as a case study provides some interesting twists in answer to De Maria's questions. The Gadfly's activities encompass, but are not limited to the public protest as conceptualized by De Maria - the speaking out against specific corruptions using the media. Its protests also include public protests against the inefficiencies of the legislation and the administrative systems that have been designed to protect whistleblowers. By bringing these issues into the public sphere, the Gadfly is attempting to shift the traditional view of whistleblowing to include internal whistleblowing. Their activities also include acts that are not considered as public protests, but are part of the activities involved in the mobilization of whistleblowing; these are acts that have engendered the creation and evolution of the Gadfly. Therefore, from here on, rather than referring to the public protests as the other locality that makes up the ethical resistance continuum proposed by De Maria, I will use the term mobilization to include the mobilized acts that do not fit with limitation of the term, public protests. Another interesting dimension that the Gadfly offers to the theoretical lens suggested by De Maria is the answer to the question regarding the possible extent of this social action movement. In the case of the Gadfly, the extent of the movement depends on the ethical resistant continuum that is available and is of interest to the individual whistleblower.

Among the Gadfly's members, there exists a diversity of paths through which ethical resisters can travel back and forth between the whistleblowing and mobilization: some 
members are blowing the whistle externally on their own cases, while actively leading the public protests on the behalf of the Gadfly; some blew the whistle in the past and are now taking the active role in the public protests; and some are blowing the whistle internally and actively leading the public protests without exposing themselves to the media. This diversity is engendered from the differences in where an individual is on the action continuum between being the reluctant dissenters to persistent ethical actors. Diversity also exists in the different advocacy actions that each individual take as a member of the Gadfly. This multiplicity brings a level of complexity to the Gadfly as a space where more than one ethical resistance continuum exists. The following demonstrates the diversity of continua and the complex connectivity between the forms of mobilized acts, the position of individuals in their whistleblowing journey, and the challenges that one faces in moving back and forth between whistleblowing and mobilization.

\section{Social Action Continua and Their Challenges}

The Case Management service was considered a tool to capitalize the collective experiences of many whistleblowers, so that the burdens of going through the whistleblowing journey are lessened for the individuals. Lessons learned from these services were meant to be shared with other members of the organization and the public at large (via the organization's website), in order to extend the benefit beyond those who seek this service and members of the Case Management team. However, the extent to which members of the Case Management team travel along the ethical resistance continuum, from being the whistleblowers to being the case workers for other 
whistleblowers, has proven to be too much because they are still affected by the burdens of their own whistleblowing journey.

All members of the Case Management team are whistleblowers (external and internal); all have gone through tremendous traumas through their personal whistleblowing experiences. With the exception of Albert, everyone else is still living through the consequences of their whistleblowing actions. For example, Irvin only finalized his legal battle with his employer in late 2010. William only resumed his position in summer 2010 after five years of receiving salary, but being denied any work. During these five years, William made several attempts of returning to his normal duties by going to the office and looking for work assignments but his efforts were fruitless. As a result, he spent most of this time at home. Irene is still trying to bring about changes by working within the system, which has proven to be challenging, and comes at a high cost to those who labor the changes. The challenges that these individuals face in their own situations create barriers in their efforts to help the whistleblowers who have come to them through the Case Management service.

All of the whistleblowers that I have encountered showed psychosomatic disorders (signs of depression, exhaustion, nervousness, anger, etc.) from having gone through the ordeal of whistleblowing; and for many whistleblowers, the situations have not, and will not find closure. Most of the whistleblowers that I have interviewed are still negotiating with the government on their cases - the negotiations can span over several years. Those who are at the later stages of their struggles express their pain with less intensity than those who are just beginning. The pain seems to subside over the years, but nonetheless the 
memories and stress remain with the whistleblowers. Even for Albert, whose whistleblowing story now serves as symbol of courage and accountability for others, still suffers as he recalls the feelings that he has had during the ordeal. Albert believes that all whistleblowers will always carry a scar: "I got over it to the extent that you can get over it. Everybody is in different stages of it, but you never completely get over it. As I said, I made the statement: we all bare scars, some of us are more visible than others. And I have them still, but they are invisible." (personal communication, November 9, 2010). The pain that members of the Case Management team experience from their individual struggles makes it difficult for them to bear witness to similar pains and struggles of other whistleblowers. As a result, all team members reported emotional, mental and physical exhaustion from conversations with whistleblowers that requested the Case Management support.

However, the strain of travelling back and forth between whistleblowing and mobilization is not limited to Case Management service. Such strain also occurs when collective actions require an individual's time and efforts to be invested into institutionalizing their solidarity such as building the business plan, drafting funding proposal, developing a processes to carry out grassroots support for whistleblowers and advocacy work. In December 2010, the directors sat together to streamline the scope of their activities - an adjustment that was desperately needed as contributing members were slowly resigning from their positions. It was decided that the organization, for now, would only focus on four main activities: the operation of the organization's website, its communication, the development of its organizational structure, and the creation of a new format of social gathering to replace the current dinner meeting. It was agreed by all directors that these 
plans would be available for discussion in the next Board of Directors (BoD) meeting in January 2011. Only one of the reports was delivered in January, because only one director actually had followed through with the plan. Incidents such as this increased frustrations among those who were involved and became the deteriorating factor in the building and maintenance of the solidarity that had existed when these members first joined the organization.

As discussed in the earlier sections of this chapter, part of the problem is the organization's position in liminality, as well as its desire to experiment with different ways to create structure. However, the other part of the problem is the magnitude to which the whistleblowing experience consumes the whistleblowers' lives. Many members are internal whistleblowers who still work for the organizations that they have blown the whistle on. During the course of my fieldwork, many members experienced nervous breakdowns, as their attempts to gain sympathy from their managers or support from the union, lawyer, governmental officials responsible for ethics and accountability continued to be fruitless. As these individuals struggled to manage their everyday lives while dealing with depression and anger, they became less able to participate in The Gadfly's activities.

The various strains on individual members created a very prominent social dynamic within the group - the lack of focus and direction as a coherent unit. In addition, the time and energy that an individual had to dedicate towards The Gadfly's activities were also dependent on their other commitments, such as family, educational pursuits, other 
volunteer activities (many members were actively involved in more than one community volunteer groups), and the recovery of their health.

Another difficulty that The Gadfly faces is trying to resolve differences in perspectives, knowledge and experiences among its most active members. The negotiation of individual ideas, perception of how these ideals must unfold in practices, and the conviction of their beliefs marginalize these whistleblowers from their organizations. These same aspects make it challenging for them to come to an agreement on how move forward in solidarity. The Gadfly faces the same challenge as that of the employers of its members - how to foster a democratic approach that is inclusive of the individuality of all its members and an accountability regime that is effective for this model of the operation. Together, these dynamics lengthen the process through which progress can occur within the organization, and consequently becomes the reasons why four out of ten directors resigned from their positions and stopped their participation in group-activities.

These different forms of mobilizations reveal the limitations of the movement between whistleblowing and mobilization. However, the tactical fluidity between whistleblowing does exist in individual actions that the Gadfly's members take in the name of the organization or as a member of the collective that is represented by the Gadfly - the whistleblowers community at large. This tactical fluidity is linked to the reasons that drive these whistleblowers to travel between whistleblowing and mobilizations. 


\section{Driving Forces Behind the Movement between Whistleblowing and Mobilization}

The discussion in Chapter Two and other earlier sections in this chapter have shown that the creation of the Gadfly as a mobilized group of whistleblowers arises from the wish of individual whistleblowers to normalize the spontaneous communitas that they found in each other during their existence in the liminal space. Part of the reason that individual whistleblowers mobilize under the name of the Gadfly is also because they realize that the sharing of knowledge and experiences of whistleblowers at different stages of the whistleblowing journey does help its members in their individual negotiation with their employers. Even though their attempt to normalize this social capital in the form of Case Management service did not succeed, the informal exchange of this information, whether thorough informal one-on-one meetings or at the newly formed Whistle Watchers meetings, has allowed participating members to benefit from this social capital. The importance of the creation of "the social spaces and institutional means" for the collective actions of individuals belonging to social groups that are subjected to "subordination and powerlessness" has been recognized for its potential in fostering a new kind of social networks, which is built on the solidarity and is engendered from the self-analysis of individuals who are subjected to the dominant political and cultural ideologies (Rankin, 2002).

Another force that drives the individual whistleblower to not only mobilize as a group in their fight for whistleblowers' protections as a measure towards anti-corruption, transparency, accountability in the public service, but also take up actions as individual ethical resisters is their self-identity as whistleblowers. Sometime after the switch from 
being the reluctant dissenters to the persistent ethical resisters, the whistleblowing experience becomes the whistleblowers' 'master status'. This master status "defines and engulfs nearly everything in their lives. Other experiences become selectively interpreted to be consistent with the master status" (Rothschild \& Miethe, 1999, p. 121).

Three out of the eleven whistleblowers that participated in this research have returned to universities for further education - all have chosen fields that are related to the subjects that they consider as important in normalizing whistleblowing in the workplace. Yan is now enrolled in the Law program at the University of Ottawa. She gave the following reason for her academic interest: "I want to represent public servants and whistleblowers that are not properly represented... That is my intention. It's not about career. It's about the cause" (personal communication, September 9, 2010). In academia, these whistleblowers exercise their agency not only as students, but also as experts in their fields. A number of whistleblowers have been invited to universities, colleges, and high school in different parts of Canada as the voice of authority on whistleblowing and workplace ethics. The recognition of their expertise on this subject is partially engendered through the individual's association with The Gadfly as its representatives; nonetheless, the invitations are often made to those whose whistleblowing stories have already been published in the mainstream media. Therefore, being known as whistleblowers also facilitate individuals' access to engage in activities that further reinforce their 'whistleblower' master status.

Other whistleblowers choose the public sphere to transform their experiences. Some share their stories by publishing memoirs of their experiences (one whistleblower became a 
writer after he left the public service), broadcasting their stories via the Internet, or by working with journalists. A number of whistleblowers are also considered as subject experts by NGOs and governmental initiatives whose mandates involve integrating the voices of authority on ethics and whistleblowing. The fact that many informants keep their master status as whistleblowers and continue to make choices that are informed by their whistleblowing experience, despite the consequences that they have faced, show that these individuals have positive self-perceptions as the result of the experience. The informants often said that regardless of the outcome of their struggles with their organizations, they could still look themselves in the mirror. However this statement is often accompanied with much regret and bitterness. Most felt that the issues of concern were not resolved in the way that they had envisioned when they first embarked on the journey, and therefore felt that the personal cost was not justified by the steps that their employers had taken to address the issues. Irvin's response to my question is an example of such bitterness:

The strength of the response against me and the evident success in the reprisal has reinforced management's hands and the sentiments all that represents. And I think in many ways it has made it worse, my case has shown that there is no legal recourse, the Office of Integrity Commissioner is clearly not fulfilling its mandate. The internal integrity officers, in my experience and others, are not doing jobs; they're just talking to management. Unions are not doing their jobs. All these mechanisms are demonstrated to fail in my case. They're all designed to suck people into thinking that they're safe. In my case, it shows that in this specific department, "this is the way things are and don't you dare speak out" if the message hasn't been clear before, it is certainly now. The department is trying to 'soft pedal' now by replacing the Minister and the Deputy Minister who were involved but the person that they replace the Minister with has no experience in the field, so she kinda is at the mercy of her senior executives who could tell her whatever they wanted to. And she doesn't have the history or background, and this could be overcome if she was highly motivated and principled person. And perhaps she is, but she is doing in the typical government way without admitting that there is a problem, without making anyone accountable, it's all very soft: moving people around and put people in training. So the message is clear: dissent 
is punished...and standing firm as a group of executives is rewarded (personal communication, September 18, 2010).

The presence of regrets, disappointments, and bitterness as expressed in Irvin's response show once again the complexity of the forces that drive some people towards the whistleblowing journey as individual ethical resisters and eventually into the ethical resistance continuum in which they temporary operate as part of a mobilized collective.

\section{Conclusion}

Whistleblowers are marginalized by their society, and yet, they find spontaneous communitas with one another through their shared experiences. However, this sense of communitas starts to waver with the decision to normalize the spontaneous union of likeminded people by bringing structure into their mobilization through the creation of the Gadfly. The shared experiences that have united the whistleblowers now become the basis for doubting whether the organization is sustainable. After almost four years of trying to institutionalize its existence, The Gadfly has returned to its starting point where coherence still only emerges through solidarity in ideals. The development of the organization has shown that the solidarity in actions is not yet found in the formalization of the organization, but rather in the shared experiences of blowing the whistle.

The challenges that the Gadfly experiences in its attempt to form what Turner calls a 'normative communitas' and what Juris calls 'a social laboratory' is part of the creative process in finding a new model of social structure that reflects the values that the group wants to see in the dominant institutionalized social structures where they have been marginalized. Not only does The Gadfly have to overcome the challenges that come with 
bringing structure to their existence, but it also has to overcome the challenges that stem from that fact that, as an organization, it is founded by a diversity of ethical resistance continua of individuals who move back and forth between whistleblowing and mobilization. While the presence of these social action continua offers many benefits to the individual whistleblowers and the larger movement that advocates for whistleblowers protection, it also presents many challenges. Therefore, the solidarity and the normalization of the communitas has not evolved as many of the Gadfly's members would wish. However, the impacts of the mobilization of what used to be the single voice of the lonesome whistleblowers have been felt not only by individual whistleblowers who have benefited from the sharing of knowledge and experiences in dealing with the challenges of blowing the whistle, but also by the larger community. Albert alludes to this bigger impact in his optimistic response to my question of whether his whistleblowing was worth it:

Did I make a difference? A minor difference, but it hasn't been enough. The only real difference is that there is a real sensitivity created in management on the issue....but they're just more sensitive to the fact that somebody could blow the whistle on them. And things like WikiLeaks...people like me, having gone, encourage things like WikiLeaks. There's been an encouragement to speak out.... The biggest change, I guess, is that fact that people look upon the fact that I speak, and they figure they can speak. And they use me as a role model (personal communication, November 9, 2010).

The difference that Albert is referring to is the accumulative result of the ways in which whistleblowers have been exercising their agency as marginalized members of the public service collective. Their experiences have provided them with an in-depth knowledge of the systems that govern the interactions between different interlocutors and an individual employee when the employee blows the whistle on the public service. This knowledge of the system has allowed The Gadfly and its allies - other national NGOs, the media, 
academia, public servants who empathize with the cause of whistleblowing, and transnational organizations such as Transparency International - to change the overall landscape of whistleblowing in Canada. The next chapter discusses the impacts of the national movement towards whistleblowers protection, that the Gadfly is a part of, on the legislation and administrative system that the Canadian state has claimed as measures designed to protect whistleblowers of the public service. 


\section{Chapter IV - THE POLITICIZATION OF WHISTLEBLOWING}

The legislative protection of whistleblowers has been advocated by the international organizations that promote social values such as transparency, anti-corruption, and accountability. These values have been associated with whistleblowing. As a result, signatory countries to international conventions such as United Nations Convention against Corruption and the Inter-American Convention Against Corruption have been working on the development and implementation of legislation and regulations to protect whistleblowers as part of their commitment towards the international movement towards anti-corruption (Transparency International, 2009: 3). Through this association, legislation and processes that provide protection for the act of whistleblowing become the tools that nation states use to politicize its efforts in achieving international standards of democracy.

While the invention of these tools takes place within the body of the state and is created to deliver a certain political effect, the control that the state has over these tools ceases to exist once they reach the public forum. In the public space, they become more than just the techniques through which the state governs its affairs and thus transforms its nation; they become the "tools for public involvement" (Asdal, 2008:13) through which nonstate actors seek to transform the state. This approach shows that "political technologies are not to be understood in a context of the microphysics of power, as techniques of domination exclusively, but as tools for public involvement, for democratization or deliberation, as well" (Asdal, 2008: 13). Therefore, the problematization of whistleblowing can be traced through the politicization of whistleblowers' protection 
legislation and its implementation, not only by the state, but also through non-state actors such as the Gadfly.

This chapter discusses how the Public Servant Disclosure Protection Act (PSDPA) and the machinery that the state has created to implement this Act, the Office of the Public Service Integrity Commissioner of Canada (OPSIC), have been politicized by the state, its politicians as well as by advocates for whistleblowers' protection. The Canadian state has created these tools in order to keep the disclosures of wrongdoings outside of politics where it can be regulated and controlled. However, the state's politicization of the PSDPA and the OPSIC has transformed them into the tools through which the public can influence how whistleblowing is addressed in Canada.

\section{The Public Servant Disclosure Protection Act (PSDPA)}

On April 15, 2007, Canada put into force the Public Servant Disclosure Protection Act (PSDPA) (Federal Accountability Act n.d.). The Act applies to most of the federal public sector - approximately 400,000 public servants (Federal Accountability Act n.d.). This legislation sets forth an approach for addressing disclosures of acts that are considered as wrongdoings in the federal public sector. The following key elements are contained within the Act: the legal definition of the wrongdoings; persons covered under the Act (employees of the federal departments, agencies, Crown corporations, and the RCMP); the disclosure process; the reprisal protection process including the definitions of reprisals; and the processes that the public service administration use to address wrongdoings (Treasury Board of Canada Secretariat, n.d.). 
Although the PSDPA is knows as the 'Whistleblowers Protection Act', its main focus is to keep disclosures of wrongdoings within the public service and outside of the public sphere. Over the last five years, advocates for whistleblowers protections, including NGOs such as the Gadfly, have transformed the Act from a tool of containment to a tool of democracy, by problematizing the aspects of the Act that protect the employer, the public service, rather than the employees. The transformation of the PSDPA is being made by instilling the public knowledge that the Act is the legal evidence that the Canadian government has made the commitment to protect whistleblowers, then scrutinizing the design of the Act as self-serving for the state. By producing a certain truth about the Act in their claim of what it should be and renouncing what it is, these advocates participate in the power struggles that shape the landscape of whistleblowing in Canada. Although the Act has not been yet been officially revised as a result of the politicization efforts - its five-year review is only scheduled for 2012 - the government already commissioned its informal review in 2008. The Act has not been revised to address the criticisms that have been put forth by advocates of whistleblowers, however the fact that an independent review has taken place four years before the official schedule suggests that its politicization, as a political technology, has transformed the Act. The following discussion details the process through which the Act has been transformed into a tool for the public involvement in debating the future of whistleblowing.

The discourse that takes place around the Act by the government and its interlocutors leads to the understanding that the Act is meant to protect whistleblowers - the Act is commonly referred to as the 'whistleblowers protection act' by whistleblowers and their advocates. However, the Act and official governmental channels, through which some 
aspects of the Act are made public, do not refer to the terms of whistleblowing or whistleblowers; instead the terminologies found in the governmental published document are "disclosure" or "the public servant who disclose" (Federal Accountability Act n.d.). The Act is concerned more with the regulations of disclosures in order to prevent them from going outside of the public service's administration system and into the political space. In other words, the PSDPA has been created to ensure that disclosures of wrongdoings in the public service are contained within an "anti-politic" space (Ferguson, 1994: 178), whereby the political character of the issues that lead to the wrongdoings and the reasons that they remain problematic within the public service are reduced to a set of seemingly neutral, unbiased, apolitical legislations for disclosures of the wrongdoings. However, the Act is inherently political and therefore its creation becomes the tool of public involvement through which non-state actors transform the discourse from regulations of disclosures to protections for whistleblowers.

Despite the lack of whistleblowing lexicon in the state's discourse, the explicit association between the state's legislation on disclosure and whistleblowing is created through national and international non-governmental actors. At the international level, one of the main actors whose work is frequently referenced in the Canadian discourse of whistleblowing is Transparency International - a global civil society that advocates for transparency and anti-corruption (Transparency International, 2009). In its 2009 publication, entitled "Alternative to Silence - Whistleblower Protection in 10 European Countries", Transparency International argues for the active role of whistleblowers in the crusade against corruption: "Whistleblowers play a vital role in exposing corruption, fraud and mismanagement and in preventing disasters that arise from negligence or 
wrongdoing" (Transparency International, 2009: 3). The production of legislation that promotes the disclosure of information and provides protection for whistleblowers by "securing their rights and ensuring a safe alternative to silence" is being raised as a pertinent component of anti-corruption mechanisms in the international forum (Transparency International, 2009: 44).

Although this discussion is situated in the European context, it acknowledges the contribution of non-governmental Canadian bodies, whose missions are related to anticorruption, namely Canadians for Accountability (C4A) and Federal Accountability Initiative for Reform (FAIR) (Transparency International, 2009: 44). The inclusion of these NGOs in such international discourse reinforces the Canadian local actors' agency and their impacts in the politics of whistleblowing. It also establishes the link between the global and local use of whistleblowers' protections legislation and their implementations as tools of public involvement.

A year after the Public Servant Disclosure Protection Act came into force; FAIR (a Canadian NGO that advocates for the protection of whistleblowers from the Canadian public service) published an explanation of the act in which it translates the legal language of the Act into "common language" (FAIR, 2008a). The Act does not refer to whistleblowers or whistleblowing. As part of the translation, at the onset of its article, FAIR explicitly draws a connection between whistleblowers and the term 'disclosure' which was used in the Act: "The person who makes the disclosure (i.e. the whistleblower)..." (FAIR, 2008a: 1). The introduction of terminology that represents certain social processes and concepts often signals specific points of emergence that 
contribute to the politicization of a given phenomenon. By looking at how these terminologies are used strategically, by whom, and at which stage of development of a certain phenomenon, it is possible to trace the impacts of lexicons on the phenomenon. The explicit association between the Act and whistleblowers transforms the Act from a tool to regulate the disclosure process, thereby keeping the exposure of problems in the administration of the state within the system and outside of the public domain, to a tool for the protection of whistleblowers used by NGOs such as FAIR to advocate for persons who blow the whistle in the interest of the public. This transformation builds a direct connection between the fate of the whistleblowers, governed by the Act, and that of the public.

The government presents the Act as a guide "to achieve a balance between the public servants' duty of loyalty to their employer and the right to freedom of expression as guaranteed by the Canadian Charter of Rights and Freedoms" (Office of Public Service Integrity Commissioner, n.d.). In this context, the employer is the public service as an institution; however many whistleblowers feel that the public itself is their employer since their salaries come from the taxes paid by the public. Ergo many whistleblowers consider that when they are exposing a wrongdoing, they are in fact being loyal to their employer. Contestations exist in the interpretation of terminologies that represent these ethical concepts. However, by engaging in the interpretation and politicization of the Act, whistleblowers have claimed the PSDPA as the symbol of the rights of public servants to blow the whistle on wrongdoings in the public service. 
The transformation of whistleblowing politics by national NGOs, such as FAIR and C4A, goes beyond claiming its protection - that is only the initial stage. The political technology of these non-state actors pervades every foundational stone on which the Act is constructed. By politicizing their criticisms of the Act, these NGOs transform the Act into a tool of democracy; thereby moving the Act from the regulated anti-political space into the political space where public opinions have led to the Parliamentary decision to revise the Act along with the complete re-organization of the governmental body that is responsible for its implementation.

Since its inception, the PSDPA has been highly criticized by most whistleblowers and organizations that advocate for whistleblowers. In 2008, FAIR published an article in which it criticized the Act heavily, claiming that it "provides only token legal support for any truth-teller who steps forward to protect the public interest, and who is likely as a result to face retaliation orchestrated by the wrongdoers" (FAIR 2008b: 1). The purpose of the document was to forewarn current and future whistleblowers not to put their faith in the statutory protection promised by the Act. The conclusion, that the Act has been carefully crafted to subject whistleblowers to an internal process that is meant to protect the system rather the whistleblowers, is made on the following criticisms of the key elements to the Act:

Although the Act erects an impressive structure of new (and costly) appointments and procedures, it does little to protect whistleblowers or the public. For example: 1) It establishes an internal administrative process that forces whistleblowers to place their fate exclusively in the hands of a newly created Commissioner, and denies them access to our normal system of public courts.

2) It provides only token legal support for any truth-teller who steps forwards to protect public interest, and who is likely as a result to face retaliation orchestrated by the wrongdoers. 
3) It provides no assurance that any wrongdoing reported by a whistleblower will be corrected: it merely calls for investigation and reporting by the Commissioner, who has no powers to order corrective action or to prosecute lawbreakers. This omission defeats the whole purpose of truth-teller coming forward (FAIR 2008b $1)$.

Others raise similar criticism concerning other nations' legislation. The United Kingdom's Public Interest Disclosure Act has been criticized for providing protection to the employer more than the employees (Thomas, 2011: 7). The Australian government is seen as discouraging disclosure of illegal and improper conducts; its critics are asking for the replacement of the current Australian Public Service Act (ibid). Although the mandatory review of the PSDPA will not take place until 2012, in 2008 the OPSIC already commissioned a scholar of Political Studies from the University of Manitoba, Dr. Paul Thomas, to provide "an evaluative framework to guide the diagnosis of what went wrong with the PSDPA and to suggest what needs to be done to improve Canada's system for encouraging, supporting and protecting public servants who disclose wrongdoing" (Thomas, 2011). This suggests that the politicization efforts of advocates for whistleblowers' protection have indeed triggered a reaction from the system.

However, legislative acts are not the only ways in which whistleblowing is politicized. International and national critics of whistleblowers' protection have put great emphasis on the availability of effective mechanisms for whistleblowers to report wrongdoings (Rothschild \& Miethe, 1999; Transparency International, 2009; Uys, 2008). While the importance of both internal and external mechanisms have been found to be crucial to effective whistleblowing, it has been documented that the availability of functional internal disclosure mechanisms will prevent disclosures from being addressed through 
external channels (Transparency International, 2009; Rothschild \& Miethe, 1999). Therefore, the creation of The Office of the Public Sector Integrity Commissioner of Canada, the Canadian authority in the implementation of the PSDPA, has also been designed as a mechanism to keep disclosures in the public service away from the political space. The mandate of this governmental body is to "strengthen public confidence in...public institutions and in the integrity of our public servants" (OPSIC, n.d.). Its scope of responsibilities includes reviewing disclosures of wrongdoing and reprisal complaints, conducting investigations, making recommendations to chief executives for corrective measures (OPSIC n.d.). However, this office and its first representative, the Integrity Commissioner - Christiane Ouimet, became highly politicized not only through the same political technologies used in the politicization of the Act, but also through the approach used to fill the position and the specific context of political landscape in which it has been created.

\section{The Office of the Public Sector Integrity Commissioner of Canada (OPSIC)}

The Integrity Commissioner position is filled through the Parliamentarian appointment process (OPSIC n.d.). The Commissioner has the same "rank and powers of a Deputy Head of a department" and reports directly to the Parliament (OPSIC n.d.). The appointment of the first Commissioner took place in 2007 under the Conservative government (Federal Accountability Initiative for Reform, 2009). This appointment addressed a promise made by the Conservative government during its 2006 electoral campaign. One of the main reasons that had been attributed to the Liberal party's defeat in 2006 was its connection to the "Sponsorship scandal". In 2004, the federal Auditor 
General, Sheila Fraser, led an investigation of the Canadian Federal Sponsorship program that had been created to support Quebec's economic development. Her critical report of the program resulted in a public inquiry headed by Justice John H. Gomery (Commission of Inquiry into the Sponsorship Program and Advertising Activities, 2005: 403). The inquiry produced evidence that the public funding assigned to the Sponsorship program had not only been mismanaged, but had also been manipulated to contribute to political activities of the Liberal Party (Commission of Inquiry into the Sponsorship Program and Advertising Activities, 2006: 5-7).

The report produced through the inquiry demonstrated how the Liberal Party had gained financial benefits through the systematic manipulation of public funding (ibid). The report provided a strong basis on which the leading opposition party, the Conservative Party, tried to convince Canadians that the entire system that governed their country needed to be changed. Gomery's report consisted of three components. The first two components outlined the investigation process, the discoveries, and the conclusion of the inquiry. The third component was a set of recommendations on how accountability could be "restored" in the public service (Commission of Inquiry into the Sponsorship Program and Advertising Activities, 2006). The recommendations included the need for a change of culture in the Canadian public service and the importance of a whistleblowers' protection legislation (Commission of Inquiry into the Sponsorship Program and Advertising Activities, 2006: 44-46). Part of the findings revealed that the "culture of entitlement" and the fear of reprisals of the involved public servants were among the major factors that resulted in the ensuing corruption (Commission of Inquiry into the 
Sponsorship Program and Advertising Activities, 2006: 5-7).

This Commission was one of the first moments when the role of whistleblowers became politicized and problematized in Canada. The Conservative Party used the recommendations in its campaign - promising to foster a change in the culture of the public service in which accountability and transparency can thrive (Conservative Party, 2006) The Conservative Party's strategic use of the Gomery report and its recommendations on disclosures of wrongdoings in order to improve accountability and transparency in the government, as part of its 2006 electoral campaign, became the political technology with which legislations as the object and the whistleblowers, as the subjects, were politicized..

However, a year after the Conservative party's victory over the Liberal party, those who had made their votes based on the promise of a reform of accountability grew impatient. They perceived that the promises had not been delivered (Cutler, 2007, p. 1). Therefore, when Christiane Ouimet was appointed to the Integrity Commissioner position by the Conservative government, she became the focal point of attention among whistleblowers and their advocates. Expectations for her to resolve issues brought forward by whistleblowers were very high.

In 2007, the President of C4A, expressed his hopes in Ouimet's appointment: "There are whistleblowers who have lost all trust in the government due to the inaction in staffing this position. They have lived in fear, communicating with me or with others. When asked, my advice has been to wait since change takes time. Finally it has arrived" (Cutler, 
2007: 2). In this context, Ouimet's role as the Integrity Commissioner was brought into the public space where her duty was politicized as the protector for whistleblowers by both the state and non-state actors; in the meantime, her role as the protector of the state's interest - the enforcer of mechanisms to ensure that disclosures of wrongdoings stay within the public administrative system and not spill over to the political space remained unacknowledged in the background. As a result, the processes and entities through which the Act was implemented quickly became the tools of public involvement. - a transformation that was facilitated through the engagement of non-state actors' in the monitoring and criticisms of the Act.

A year after the politicization of her role as the protector for whistleblowers and manifestation of the Conservative government's ethical platform, the political dynamics shifted as Ouimet was reconfigured into an icon of the dysfunction and proof that wrongdoings were still being cultivated in the Conservative led public service (Mayeda, 2009: 1). In 2008, C4A publicly criticized Ouimet's work in the Hill Times: "That she asserts that there aren't any systemic problems begs the question: is she simply poorly informed or, as a former ADM (Assistant Deputy Minister) of Agriculture, is she still part of the culture of entitlement? In addition, the fact that she has not initiated contact with either FAIR or Canadians for Accountability makes us question her assertion that she is reaching out" (Cutler and Bron, 2008: 8). In 2009, after having served less than two out of the seven year appointment, Ouimet was asked to resign from her position by FAIR in an interview by National Post: "It's not polite to call for an agent of Parliament to be removed, but it's very hard to see how Madame Ouimet can salvage her reputation" (Mayeda, 2009: 1). 
In response to the public criticisms from these advocacy groups, in 2010 , two years after her appointment, Ouimet started to engage representatives of the C4A and FAIR. Both sides publicized these interactions. One such occasion was the recent Office of the Public Sector Integrity Commissioner (OPSIC) symposium in which roughly 80 governmental senior bureaucrats responsible for departmental internal investigations met to discuss Canadian federal whistleblowers' protection legislation (Federal Accountability Initiative for Reform, 2010: 1). For Ouimet, the interactions served as a representation of her office's goodwill to collaborate with advocacy groups that represented the people whom her office had been mandated to serve (OPSIC n.d.). For advocates, this interaction further increased their agency in transforming the OPSIC and its Integrity Commissioner into the tools for public involvement in the shaping of the Canadian whistleblowing politics. This is evident in the Executive Director of FAIR, David Hutton's closing remarks in an article in which he shared his perspectives on the OPSIC symposium: "We also look forward to collaborating with the Commissioner to build a better system that will provide whistleblowers with genuine and meaningful protection" (Federal Accountability Initiative for Reform, 2010: 2).

Despite the late efforts to engage interest groups, Ouimet's progress was still highly challenged by the whistleblowers. For example, since her appointment, Ouimet had annually reported to the Parliament that there was no wrongdoing in the Canadian public service (OPSIC n.d.). According to the third annual report, OPSIC (2010) found no systemic problem that led to wrongdoings in the Canadian public service in the 20092010 fiscal year. At the time of the report publication, the OPSIC processed 71 
disclosures (OPSIC, 2010). Out of these, only two proceeded to formal investigation and none warranted corrective recommendation from OPSIC (OPSIC, 2010). Similarly, 19 people had complained about reprisals resulting from disclosures and none of these complaints entered conciliation or proceed to tribunal (OPSIC, 2010). These findings angered whistleblowers and the advocacy organizations that had been experiencing a significant increase in the number of calls for help from public servants who perceived wrongdoings in their organizations during the same timeframe.

By this time, according to critics of the OPSIC, Ouimet was no longer seen as the symbol of the state's morality as it was when the Conservative government was running for election. The end of 2010 marked a significant turning point in the Canadian politics of whistleblowing. In October 2010, Ouimet resigned from her position in the midst of the Auditor General's investigation of her performance as the leader of OPSIC - this investigation occurred because of three internal complaints made to the Auditor General's office by OPSIC employees in 2008 and 2009 (Office of the Auditor General of Canada, 2010). Ouimet's employees used the internal disclosure mechanisms, available to them through the Auditor General's office, to blow the whistle on the operations of OPSIC under Ouimet's leadership. In December 2010, the Office of the Auditor General, represented by Sheila Fraser, produced the following conclusion in their special report to the House of Common: "In our view, the Commissioner's behavior and actions do not pass the test of public scrutiny and are inappropriate and unacceptable for a public servant- most notably for the Agent of Parliament specifically charged with the responsibility of upholding integrity in the public sector and of protecting public servants from reprisal" (Office of the Auditor General of Canada, 2010). Ouimet's exit 
as the Integrity Commissioner position was just as politicized as her entry. However, the politicization of Ouimet had a different twist this time. The Auditor General's report provided evidence against Ouimet as a person, but not against the state. Therefore, this moment of politicization condemned the individual and, at the same time, re-established the state's use of the moral logics to enforce its disclosure regime.

\section{Conclusion}

The politicization of whistleblowing was triggered by the efforts to politicize the PSDPA and the OPSIC from the Canadian government, political parties, and organizations that advocate for whistleblowers' protection. Each group politicizes the legislation, the administrative system and the individuals that have been put in place to implement the legislation, for their own purposes. The objective of the political parties and the Canadian government is to maintain or to increase their political power by demonstrating their responsiveness to the global and national push of governments towards anti-corruption measures that promote accountability and transparency. The objective of advocates for whistleblowers' protection is to transform these components of the disclosure regime into tools through which whistleblowing can be used to minimize and confront corruptions in the public service.

The defeat of the Liberal party in the 2006 election shows that the political technology employed by the Conservative party was effective. However, once the Conservative party won the seat of power, the effect of the politicization of the PSDPA and the OPSIC did not work in their favour. As the leader of the government, the Conservative party 
now faces the dilemma of being held accountable for the effectiveness of whistleblowers' protection measures - a development that has been acknowledged as an important change in the political campaign that led to its rise in power - while facing the risk that whistleblowing may expose the wrongdoings of the government that it is now responsible for. These tools are designed to serve the purpose of keeping whistleblowing inside the public service rather than protecting whistleblowers; therefore, contradictions arise when the government politicizes these tools in its continual effort to secure the seat of power. These contradictions are quickly picked up by advocates for whistleblowers' protection, who in turn politicize both tools and the contradictions between the government's claims on these tools and the underlining purpose of their architecture, as a way to be involved in the process of shaping the role of whistleblowing in the public service.

The effectiveness of the politicization efforts of these advocates can be seen in the informal review of the PSPDA that took place four years before its schedule and the recent organizational changes within the OPSIC. We have yet to see whether these changes will address the concerns that have been raised by advocates of whistleblowers, or lead to effective protection for whistleblowers, or transform whistleblowing into an integrated part of the anti-corruption measures for the public service. Nonetheless, the fact that the PSDPA and the OPSIC, as components of the disclosure regime, are being put into question and conversations are taking place between the government and these advocates, already demonstrate that the efforts of advocates, such as the Gadfly, are transforming the whistleblowing landscape of Canada. 
The dynamics described in the politicization of the Act and the Integrity Commissioner demonstrates the relational characteristic of government that Foucault emphasizes in the study of governmentality. The described ongoing transformation of whistleblowing in Canada is the result of the power relations between the different actors found in this landscape. The power struggles between the state, the political parties, the advocates for whistleblowers' protection, and the interlocutors that are involved with these interest groups give rise to what we know as whistleblowing today, which is starting to shift from what it was before the Sponsorship scandal came under investigation in 2004. Whistleblowers are no longer known as the individual dissenters who are condemned for the disloyalty towards their organizations; instead, conversations are beginning to take place on how whistleblowers can be used as an asset in the fight against corruption towards transparency and accountability in the public service and the protection that should come with this role. This shift does not happen in a linear development, but rather as a result of specific moments in which the different ideologies are played out in the negotiations involving the PSDPA and OPSIC - these negotiations are still ongoing. By looking at the power relations between the different actors and the impacts of the negotiations in interests and ideologies through the developments of the PSPDA and OPSIC, the interconnections between actors and their impact on the overall whistleblowing landscape can be revealed. Since the past always informs the future, these revelations may contribute to the conversations that are shaping the future of whistleblowing. 


\section{Chapter V-CONCLUSION}

The Gadfly, as an organization composed of mostly whistleblowers, represents the transformation that is currently taking place in the whistleblowing landscapes of Canada. Its creation provides evidence that whistleblowing is no longer just isolated cases of individuals' struggles against their employers. The individual struggles are still a part of the whistleblowing experience, but whistleblowers are now also a part of the larger collective that advocates for changes in public institutions. The Gadfly members now have the choice to travel back and forth between the traditional lonesome ethical whistleblowers and members of a larger collective who advocate for whistleblowers' protection at the national and global level. This action continuum offers many advantages. It provides whistleblowers the opportunities to meet people with whom they share a sense of spontaneous communitas during a time when they are struggling to cope with the marginalization that comes with being a whistleblower. It provides a social space where whistleblowers can collectively analyze their situation and learn from each other's experiences. The Gadfly also provides the potential for these whistleblowers to transform the solidarity that they have in principles into actions, and the potential to actively transform the whistleblowing landscape of Canada specifically, and the Canadian public service at large; however, the Gadfly is not there yet.

It is significant that the same factors that create the solidarity in principles among the Gadfly's members also create challenges that the organization must overcome in order to move forward with its vision. In order to move towards the shared vision of being the voice that advocates for accountability and transparency in the public service through 
whistleblowers' protection measures, the Gadfly tries to bring structure into their existence while they attempt to maintain the spontaneous communitas that existed when they first discovered each other as fellow whistleblowers. However, the spontaneous communitas that led to the formation of the Gadfly cannot be maintained once structure is introduced into the existence of the collective. The struggles that the Gadfly goes through in trying to establish structure in its existence is partly due to its desire to maintain the spontaneous communitas while trying to establish a structure based on the knowledge of former institutionalized structures from which its members have been marginalized, the liminality existence that both the organization and its members are experiencing, and the action continuum that takes them back and forth between being whistleblowers and members of the collective.

Moving through a social action continuum between whistleblowing and mobilization, the Gadfly's members enter a negotiation of power, not only with the interlocutors involved in their individual whistleblowing experience, but also with each other. Emerged from their collective experiences as individual ethical resisters, members of this organization are trying to establish a functioning structure that can move them into a solidarity not just in principles but also in actions. The hope is that by moving out the liminal phase, they will be able to further penetrate the web of local and global power relations that are shaping the politics of whistleblowing. As a collective that challenges the status quo of the Canadian public service's organizational norms while trying to engender new political imaginaries, they are struggling to put the "prefigurative and strategic dimension" (Juris, 2008: 290, citing Breines, 1989) of their ideals into practice. The Gadfly's success is dependent upon whether they can walk the path that they are essentially asking the 
Canadian public service to embark on - a deliberative democracy that is coupled with an effective accountability regime.

The Gadfly's struggle to move forward with their objectives, and being stuck in the ongoing debates on how to formalize themselves, could be the result of their attempt to cultivate a deliberative democracy among the Board of Directors and an expansive democracy because it occasionally seeks consensus among all Gadfly members during its Annual General Meetings (AGMs) or former social dinner meetings. However, if The Gadfly is indeed trying to achieve deliberative and/or expansive democracy, it will need to adopt an accountability regime - that will allow for a successful operationalization of this philosophy. Ebrahim (2009: 889) suggests that NGOs consider the "adaptive accountability regime" that focuses on the core of the organization: its motivating visions, mission, and key activities, and how it frames social problems. The reason why this accountability regime is especially suitable for NGOs like The Gadfly is because it operates on the basis that solutions to social problems must integrate the uncertainty and non-static factors of circumstances. Therefore, the mode of operation to be adopted is the "organizational learning" in which the organization adapts its goals and strategies through systematic critical reflection and adjustments to the changing circumstances, while maintaining a focus on its mission (ibid). The flexibility and adaptability in this accountability regime echo the approach that the Gadfly is struggling to create in its efforts to operate under the deliberative and expansive democracy. Elster (1998) offered the concept of "deliberative democracy" or "decision making by discussions among free and equal citizens" that is created through "the transformation (rather than simply the aggregation) of preferences" (as cited in Asdal, 2008: 20). This concept has a historical 
context dated back to the French Revolution in 1789 - during this time, the same approach was used to demand that political decisions be made based on changing one's opinion in order to collectively form a common will, rather than on the fixed interests and ready-made opinions (Asdal, 2008: 20, citing Elster). The deliberativeness and expansiveness of this democracy may perhaps provide the fertile ground for the reconceptualization of loyalty and accountability, represented by the legislation that have been created for the protections of those who choose dissent over silence when their ethics are tested by the perception of rights and wrongs.

It is still too early to determine whether or not the Gadfly will be successful in establishing a functional and sustainable normative communitas, and whether the work of the organization will result in the desired changes to the legislation and administrative processes that the Canadian government has created to address the national and global call for whistleblowers' protection. However, the impact that the Gadfly has made to the collective advocacy effort for better whistleblowers' protection measures can already be seen in the national and personal levels.

The early review of the PSDPA and the organizational changes within the OPSIC demonstrate that the political technologies that The Gadfly's members and the organization use to convert whistleblowing legislation and processes of the state into tools of public involvement have transformed the landscape of whistleblowing at the national level. At the same time, the changes that are taking place at the national level have also become the political technologies that international NGOs, such as Transparency International, use as leverages to mobilize the global movement against anti-corruption. 
The politicization at the global scale becomes the tool that national organizations, such as the Gadfly, use to exert the international pressure on the Canadian government, and to address the concerns of Canadian whistleblowers within the political boundaries of their organizations. The knowledge produced through critical reflection on the problems found in the integration of whistleblowing into the anti-corruption platform represents a source of support that whistleblowers and advocates for whistleblowers' protection could incorporate in their endeavors to move Canada towards the global movement against corruption.

At the personal level, the individual whistleblowers change their immediate environment by making the rationale for their dissent and resistance against the norms of the organization known to others within and/or outside of their organizations. By choosing to share their experiences, they helped each other and other interested interlocutors, such as myself as a researcher, to be better informed of the experiences of whistleblowing in Canada. Unlike the traditional view of whistleblowing, to blow the whistle in the Canadian public service at this time means engaging in a negotiation of individual ethical positions and understanding of the institution's mandate with the norms of the organization. Therefore, most whistleblowers are not fighting against the corruption that focuses on the theft of public funding, but rather on those that weaken the public trust in the institution or the effectiveness of the institution to carry out its mandate. This new conceptualization of corruption addresses the challenges that whistleblowers face in finding support in their organizations where corruption is still seen in its traditional form, and the interest in building careers and the cost of dissent still out-weigh the responsibility to be consistent with the mandates and principles professed by the 
organization. The journey from being a reluctant dissenter to the persistent ethical actor is revealed to new whistleblowers who come to the Gadfly. Although they may not get the help that they seek from the Gadfly, they do walk away with the knowledge and the shared experiences of those who are further ahead on the path of whistleblowing.

This ethnography bridges the gap between current research on the state's concerns with the efficiency of its whistleblowing mechanisms (Thomas, 2011) and whistleblowers' concerns with the availability of effective protection to encourage rational loyalty. It tries to engage the depth and multiplicity of the whistleblowers' experience in order to unveil influential factors that shape the landscape of whistleblowing. However, the current research only presents a fraction of complexities to be found in this subject. This research provides the connections between the individual and the collective experiences, between legislation, its translation, and its impacts. Its analytical scope is limited to the patterns of experiences of the whistleblowers. The ethnographic data suggests that a deeper engagement of the construction of ethics, from a psychoanalytical lens, would allow for a better understanding of why differences exist in how individuals negotiate their own ethics with those of the dominant culture.

In addition, the data that informs this research is also limited to the level of trust that The Gadfly has towards me as a researcher. Although at the onset of the research I was granted full access to many meetings and correspondences, there were exchanges in which I was not invited to participate. I only learned of the developments of these exchanges through conversations with individual whistleblowers. Therefore, an understanding based on multiple perspectives on these developments was often not 
possible. Furthermore, although the intention of this research was not to engage into the details of each whistleblowing case, throughout the research, it became evident that knowledge of the details of these cases would present a valuable dimension on this subject. It especially would have offered an intimate understanding of the current accountability regime of the Canadian public service. However, within the limitations of a MA thesis, these dimensions were not included.

\section{Opportunities for Future Research}

A number of other dimensions also emerge strongly from the ethnographic data. Capturing these dimensions would require a larger project; nonetheless, they present captivating research opportunities and the resulting knowledge would contribute significantly to the efforts of transforming whistleblowing into an effective tool for the global anti-corruption movement. The three subjects that emerge most strongly from the ethnographic data as areas needing further research are: the need to engage the perspectives of the whistleblowers' antagonists; the exploration of how political technologies grounded in digital technological advancements impact whistleblowing; and the analysis of other forms of whistleblowing such as those employed by people whose advocacy is not informed by their personal whistleblowing experiences.

\section{Perspectives of Whistleblowers' Antagonists}

The influence of leadership and cultures of the government have been raised as essential to the success of not only the disclosure regimes, but also to the effectiveness of 
whistleblowing as an anti-corruption practice. The following prescription has been offered as conditions for effective disclosure regime in the South African context (Uys, 2008: 918):

A climate of disclosure needs to be institutionalized through implementing clear and open communication channels, a flat hierarchical structure and promoting reciprocal relationships of trust. It also entails creating a corporate environment where the focus with any disclosure will be on the message rather than the messenger. This involves assurance of non-victimization to prospective whistleblowers, the implementation of whistle blowing procedures, including sanctions against perpetrators of retaliation, the investigation of the whistleblower's claims by an independent agency and the provision of support to whistle- blowers. It requires a change in corporate values, where business ethics are taken seriously.

The recognition of the importance of leadership in the development and implementation of an effective disclosure regime is echoed in Dr. Paul Thomas's recommendations for the mandatory review of the PSDPA that has been scheduled for 2012 (Thomas, 2011: 2):

detailed legislative provisions, structural arrangements and ongoing parliamentary scrutiny were less important to the early poor performance of Canada's disclosure regime than the combined impacts of leadership on several levels and, the closely related values and norms of behavior in the overlapping political and administrative cultures of government which in the contemporary context have been dominated by considerations of tight control over information and messaging about the performance of government. A diagnosis which emphasizes the crucial importance of the elusive phenomena of leadership and culture poses problems for would-be reformers because seeking improvement through these factors is both a more problematic and longer term approach than amending legislation and creating new structures and processes.

Thomas (2011) is calling attention to the role of the leadership in the public service in the interpretation and application of the Canadian disclosure regime's existing legislation and organizational framework. He believes that leaders, in both of the public administrative and political arms and throughout all levels within the state's hierarchy, play a significant role in transforming the organizational culture of the public service towards "rightdoing 
and zero-tolerance for wrongdoing" (Thomas, 2011: 8). However, the change that is associated with whistleblowing, involves a much more paramount shift in the culture of the Canadian public service - it requires a different understanding of wrongdoing.

The most difficult task that the Canadian leadership faces is not addressing the "bad apples,' but rather unveiling the institutional corruption that whistleblowers in the Gadfly argue is pervasive throughout the public service - the corruption that leads to the collision between OPSIC's report of no wrongdoing, and the experiences of whistleblowers who are outraged by this finding. And perhaps in doing so, Canada's public service and its politicians will be able to begin to cultivate the conditions that De Maria has described as effective for whistleblowing. Just as this ethnography has engaged in a thick description in order to reveal how whistleblowers interpret wrongness, loyalty and the purpose of the Canadian disclosure regime, a similar ethnography should be conducted with the state's representatives to explore the same subjects. The ethnography should include the antagonists of whistleblowers, since most of them represent the leadership that Thomas is addressing in his recommendations. Documenting the differences and similarities in the worldview of whistleblowers and their antagonists could lead an informative discussion of how institutional corruption can be addressed.

\section{Digital Technologies as Political Technologies}

Today's information technological advancements play a crucial role in the global cultural shift towards accountability and transparency. In the recent years, the Canadian public service has developed rules and regulations on how business is to be conducted in order 
to achieve objectives such as transparency, accountability, and ethical conducts. The Canadian government has legislated two Acts through which certain information in the federal government records can be accessed by the public: the Access to Information Act, which gives Canadians the right to access information in federal government records, and the Privacy Act that provides the right to access personal information held by the government and protection of that information against unauthorized use and disclosure; together they are referred to as ATIP (Treasury Board of Canada Secretariat, n.d.). The majority of my informants extract information about themselves and their whistleblowing cases using ATIP in order to gain an understanding of the events that led them to be marginalized by their organization. However, most complain that the materials are overwhelming and difficult to understand. Messages are often coded so that the readers must possess a certain level of insider knowledge in order to decipher its meaning. In addition, information that is considered confidential is blackened out in these documents; even though, very often, such information is essential to the understanding of how each whistleblowing case unfolds from the perspective of the employer. Some whistleblowers have reversed the situation. Instead of being discouraged by the limitations of this information, they have adopted the WilkiLeaks approach whereby they release these documents into the public sphere by putting them on personal websites. Therefore, the emergence of open source websites such as WikiLeaks and networking forums such as Twitters, Blogging and Facebook, have become tools that the public use to, not only engage, but demand their involvement in the government of the public life. The Internet also provides several other forums through which information on whistleblowing is transmitted by a multitude of interest groups across the world. An ethnography following the political technologies found in the information digital space of whistleblowing politics, 
which is used as tools of domination by the state and as tools of public engagement by non-state actors, would be extremely informative for the understanding of current and future transformation of this social phenomenon.

\section{Blow the Whistle without Being the Whistleblower}

The research on The Gadfly was partly informed by those of its members whose involvement with the organization did not stem from their personal whistleblowing experiences. Their advocacy work is motivated by: a shared ideology that whistleblowers play an important role in the improvement of the public life; personal relationship with whistleblowers who are members of The Gadfly; or professional interests in the subject. They share many similarities with the whistleblowers that I interviewed. Their personal backgrounds resonate with those of the whistleblowers, in that they often find themselves questioning the norms of their environments. Whether through their direct engagement with the state, such as the politicization of the PSDPA's ineffectiveness via the media or their support on ATIP requests for whistleblowers, their involvement with The Gadfly contributes to the exposure of the state's problems in the public sphere. Although they have never blown the whistle on their employers, the data that emerge from my interviews suggest they may constitute a different group of whistleblowers. However, further research on these members is necessary to further expand on this hypothesis. 


\section{Conclusion}

Whistleblowing was previously understood to be isolated events that result from individuals' actions. Discourse on whistleblowing traditionally focuses on the debate between the act being heroic or not, while also focusing on the repercussions that individual whistleblowers endure (Alford, 2002). This ethnography reveals a current development within the Canadian public service in which whistleblowing has gone from individual experiences to a social movement - one that has the promise to operationally and philosophically change the organizational culture of the Canadian government. With the presence of the Gadfly and other advocates of whistleblowers' protection, whistleblowers are starting to join forces to share with each other the experiences of being the marginalized - an act that not only provides the emotional support for each other, but also creates a social space that allows for the building of solidarity, which challenges the dominant ideologies of the public service. Their organizational naivety has transformed them from the reluctant dissenters, who hope for consistency between the organization's values and its practices, to persistent resisters who demand that rational loyalty is not to be rewarded with retaliations.

In this new social space created by The Gadfly, the whistleblowers systematically analyze their position of subordination and powerlessness to unveil the norms and practices that are found in the act of whistleblowing. These commonalities are engendered by the government's system of response to the people who choose to bring attention to disparity between their expectations of the organization and what they actually experience as a member of the organization. Collectively, they have positioned themselves as a symbol of 
a civil society that participates in the evolution of the Canadian public service giant. However, the sheer size of the giant requires that they not only use public criticism but also strategies through which the giant can be coaxed into the terms of agreement. Through these means, whistleblowing becomes one of the tools that Canadians employ to implement the democratic ideals promoted by their government. 


\section{BIBLIOGRAPHY}

Alford, F. C. (2002). Broken Lives and Organizational Power. New York: Cornell University Press.

Asdal, K. (2008). On Politics and the Little Tools of Democracy: A Down-to-Earth Approach. Distinktion, 16, 11-26

Besley, T. (2005). Foucault, truth telling and technology of the self in schools. Journal of Educational Inquiry, 6(1), 76-89

Briggs, C. (1996). The Politics of Discursive Authority in Research on the 'Invention of Tradition'. Cultural Anthropology, 11(4), 435-69.

Chopra, S. (2009). Corrupt to the Core - Memoirs of a Health Canada Whistleblower. Caledon, ON: Kos Publishing

Commission of Inquiry into the Sponsorship Program and Advertising Activities. (2005). Who Is Responsible? (Cat. No: CP32-86/2-2005E. ISBN: 0-660-19533-X). Ottawa, ON: Publishing 'and Depository Services - Public Works and Government Services Canada

Commission of Inquiry into the Sponsorship Program and Advertising Activities. (2006). Restoring Accountability (Cat. No: CP32-86/3-2006E. ISBN: 0-660-19534-8). Ottawa, ON: Publishing and Depository Services - Public Works and Government Services Canada

Cutler, A. (2007). Public sector integrity commissioners: appointment a long time coming. The Hill Times, 30 April, pp. 1-2.

Cutler, A. and Bron, I. (2008). Public Servants Still Coming Forward With Serious Concerns, Fears of Reprisals. The Hill Times, 27 October, pp. 1-2.

De Maria, W. (2008). Whistleblowers and Organizational Protesters: Crossing Imaginary Borders. Current Sociology, 56 (6), 865-883.

Ebrahim, A. (2009). Placing the Normative Logics of Accountability in "Thick" Perspective. American Behavioral Scientist, 52(6), 885 - 904.

Edmond J. Safra Foundation Center for Ethics. Harvard University (2009). Request for Proposals for the Lab - Project on Institutional Corruption. V1. Cambridge: Lessig, L.

Englund, H. (2006). Prisoners of Freedom: Human Rights and the African Poor. Berkeley: University of California Press.

Elster, Jon (ed). (1998). Deliberative Democracy. Cambridge: Cambridge University. 
Federal Accountability Initiative for Reform. 2008). Public Servant Disclosure Protection Act Explained. Ottawa, ON: Hutton, D.

Federal Accountability Initiative for Reform. (2008). What's Wrong with the Public Servants Disclosure Protection Act. Ottawa, ON.

Federal Accountability Initiative for Reform. (2009). Five Things Canada's Public Sector Integrity Commissioner's Office Should Do Right Now. Ottawa, ON: Hutton, D. And Kilgour, D.

Federal Accountability Initiative for Reform. (2010). Bureaucrats Meet to Discuss Whistleblower Law. Ottawa, ON: Hutton, D.

Ferguson, J. (1994). The Anti-Politic Machine "Development" and Bureaucratic Power in Lesotho. The Ecologist, 24 (5), 176-181.

Foucault, M. (1982). The Subject and Power. Critical Inquiry, 8 (4), 777-795.

Hale, C. (2006). Activist Research v. Cultural Critique: Indigenous Land Rights and the Contradictions of Politically Engaged Anthropology. Cultural Anthropology, 21(1), 96120.

Juris, J.S. (2008). Networking Futures: The Movements Against Corporate Globalization. Durham and London: Duke University Press.

Keesing, R. (1989). Creating the Past: Custom and Identity in the Contemporary Pacific. Contemporary Pacific, 1(1 and 2), 19-42.

Mayeda, A. (2009, July 5). Calls for Whistle-Blowing Watchdog to Step Down. National Post, pp. 1-3.

Office of the Auditor General of Canada. (2010). Report of the Auditor General of Canada to the House of Commons - The Public Sector Integrity Commissioner of Canada (Cat. No. FA3-66/2010E-PDF. ISBN 978-1-100-17430-3). Ottawa, ON: Office of the Auditor General of Canada.

Office of the Public Sector Integrity Commissioner of Canada. (2010). Annual Report 2009-2010 (Cat. No.: PG1-2010E-PDF. ISBN: 978-1-100-15810-5). Ottawa, ON: Office of the Public Sector Integrity Commissioner of Canada.

Ranco, D. J. (2006). Toward a Native Anthropology: Hermeneutics, Hunting Stories, and Theorizing from Within. Wicazo Sa Review, 21(20), 61-78.

Rankin, K. N. (2002). Social Capital, Microfinance and the Politics of Development. Feminist Economics, 8(1), 1-24. 
Rothschild, J. and Miethe, D. T. (1999). Whistle-Blower Disclosures and Management Retaliation. The Battle to Control Information about Organization Corruption. Work and Occupations, 26(1), 107-128.

Scheper-Hughes, N. (1995). The Primacy of the Ethical: Propositions for a Militant Anthropology. Current Anthropology, 36(3), 409-440.

Scheper-Hughes, N. (2007). The tyranny of the gift: Sacrificial violence in living donor transplants. American Journal of Transplatation, 7(3), 507-511.

Thomas, G.P. (2011). Problems with Canada's Public Servants Disclosure Protection. Optimum Online, 41(1), 1-14.

Transparency International (2009). Alternative to Silence - Whistleblower Protection in 10 European Countries. Germany, Berlin: Osterhaus A. and Fagan C.

Turner, V. (1969). The Ritual Process. Chicago: Aldine Publishing Company.

Turner, V. (1982). From Ritual to Theatre. New York: Performing Arts Journal Publications.

Unknown (2005, November 23). Sponsorship whistleblower to run for Tories. CBC News. pp. 1-2.

Uys, T. (2008). Rational Loyalty and Whistleblowing: The South African Context. Current Sociology, 56(6), 904-921.

Westhues, K. (2002). At the mercy of the MOB. $O H \& S$ Canada, 18(8), 30-36.

\section{Websites:}

Anthropologi.info (August 7, 2009). Retrieved November 10, 2011

(http://www.antropologi.info/blog/anthropology/2009/nancy-scheper-hughes-on-publicanthropology).

Canadians For Accountability (C4A) (n.d.). Retrieved April 9, 2010

(http://www.canadians4accountability.org/news/main-e.html).

Conservative (February 01, 2006). Retrieved August 8, 2011.

(http://www.conservative.ca/EN/1091/40410

Federal Accountability Act (n.d.). Retrieved April 9, 2010 (http://www.faalfi.gc.ca/index-eng.asp). 
Federal Accountability Initiative for Reform (FAIR) (n.d.). Retrieved April 9, 2010 (http://fairwhistleblower.ca/news/articles/2009-07-05_Calls_for_whistle blowing_watchdog_to_step_down.html).

Office of the Commissioner of Official Languages (n.d). Retrieved July 24, 2011 (http://www.ocol-clo.gc.ca/html/charter_charte_e.php)

Office of the Public Sector Integrity Commissioner of Canada (OPSIC) (n.d.). Retrieved April 9, 2010 (http://www.psic-ispc.gc.ca/quicklinks_liensrapides/articles-en.aspx).

Service Canada (n.d.). Retrieved July 19, 2011

(http://www.servicecanada.gc.ca/eng/ei/information/misconduct.shtml).

Treasury Board of Canada Secretariat (n.d.). Retrieved July 19, 2011 (http://www.tbssct.gc.ca/pubs_pol/hrpubs/pensions/yppl-eng.asp\#Toc497204656) 